\title{
Investigation of ecological behavior of two Coccinellidae beetle adults for biological control
}

\author{
Folukemi Ebunoluwa Adedipe \\ West Virginia University
}

Follow this and additional works at: https://researchrepository.wvu.edu/etd

\section{Recommended Citation}

Adedipe, Folukemi Ebunoluwa, "Investigation of ecological behavior of two Coccinellidae beetle adults for biological control" (2009). Graduate Theses, Dissertations, and Problem Reports. 2790.

https://researchrepository.wvu.edu/etd/2790

This Thesis is protected by copyright and/or related rights. It has been brought to you by the The Research Repository @ WVU with permission from the rights-holder(s). You are free to use this Thesis in any way that is permitted by the copyright and related rights legislation that applies to your use. For other uses you must obtain permission from the rights-holder(s) directly, unless additional rights are indicated by a Creative Commons license in the record and/ or on the work itself. This Thesis has been accepted for inclusion in WVU Graduate Theses, Dissertations, and Problem Reports collection by an authorized administrator of The Research Repository @ WVU. For more information, please contact researchrepository@mail.wvu.edu. 


\title{
INVESTIGATION OF ECOLOGICAL BEHAVIOR OF TWO COCCINELLIDAE BEETLE ADULTS FOR BIOLOGICAL CONTROL
}

\author{
Folukemi Ebunoluwa Adedipe
}

Thesis submitted to the College of Agriculture, Forestry and Consumer Sciences, Division of Plant and Soil Sciences at West Virginia University in partial fulfillment of the requirements for the degree of

\section{Master of Science}

in

Plant and Soil Sciences - Entomology

\author{
Yong-Lak Park, Ph.D., Chair \\ Henry W. Hogmire, Ph.D. \\ Rakesh Chandran, Ph.D \\ Morgantown, West Virginia \\ 2009
}




\section{ABSTRACT \\ INVESTIGATION OF ECOLOGICAL BEHAVIOR OF TWO COCCINELLIDAE BEETLE ADULTS FOR BIOLOGICAL CONTROL}

\section{Folukemi Ebunoluwa Adedipe}

Biological control is the use of natural enemies, which is an effective strategy to control and suppress pest populations in a given agroecosystem; however farmers are not motivated to adopt this method because of the high cost and temporal unavailability of natural enemies.

This thesis is based on reports on findings of a series of laboratory experiments carried out to investigate ecological behavioral of two major natural enemies (i.e. Harmonia axyridis Pallas (Coleoptera: Coccinellidae) and Cryptolaemus montrouzieri Mulsant (Coleoptera: Coccinellidae). Firstly, study was conducted to determine if $H$. axyridis could be attracted into cropping areas using companion plants with different olfactory and visual cues. Ten potential plants that can attract and provide $H$. axyridis with nectar and pollen were selected for a preference test. The result of the olfactory preference test showed that there was significant difference in the plant preference by $H$. axyridis; sunflower was the most preferred attractant plants. In a visual preference test, $H$. axyridis preferred yellow to other colors. Secondly, study was conducted to investigate within-plant distribution of long-tailed mealybug, Pseudococcus longispinus (Targioni-Tozzetti) (Hemiptera: Pseudococcidae) to quantify the searching and handling time of $C$. montrouzieri on three different plants heights and to determine preference of C. montrouzieri to the size of $P$. longispinus. P. longispinus were found more on the upper parts of the plants regardless of the height. The time $C$. montrouzieri spent to find the first $P$. longispinus was significantly $(P<0.05)$ different among the three different plant heights at two different releasing points. However, there were no significant differences in handling time and cleaning time. $C$. montrouzieri preferred smaller size of $P$. longispinus to medium and larger size. The finding of results in this thesis suggested that $H$. axyridis and $C$. montrouzieri can potentially be used as economical and sustainable biological control agents. 


\section{DEDICATION}

To my lovely children Iseoluwa and Ewaoluwa Adedipe, they are the source of my joy.

$\&$

To all that have contributed to my academic successes. God bless you all. 


\section{ACKNOWLEDGMENTS}

I believe that I could not have done this with my strength alone; however he made all things beautiful in his time. I acknowledge the Almighty God for exercising his loving kindness and power over my life.

I would like to thank the Davis College of Agriculture Forestry and Consumer Sciences for allowing me to take part in graduate studies at West Virginia University.

I would like to express my sincere appreciation to the members of my graduate study committee, Dr. Henry Hogmire and Dr. Rakesh Chandran for their time, discussions and valuable comments over the course of this project. I wish to express my profound gratitude to my major advisor, Dr. Yong-Lak Park, for his encouragement, invaluable advice and genuine interest that has made a success of this study at West Virginia University.

I'm particularly grateful to Vicki Kondo for her time, suggestion and help in collecting insects that was used for this study; she has played an essential role in the thesis completion. Also I will like to thank JB White, who has just graduated, for his much help during the course of my study at West Virginia University.

My deepest gratitude goes to my parents for always struggling to live up to their responsibilities against all odds and constraints. I owe a large debt of gratitude to my husband Oluwatosin Adedipe, who has been there for me and endured this process all along the way. I'm really amazed at how much he loves and sacrifices for me. I could not have done this without him. 


\section{TABLE OF CONTENTS}

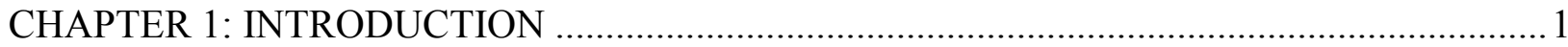

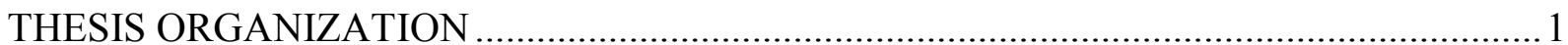

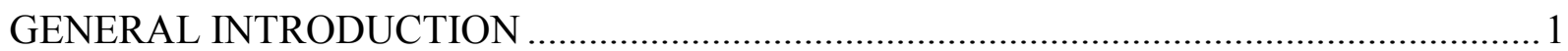

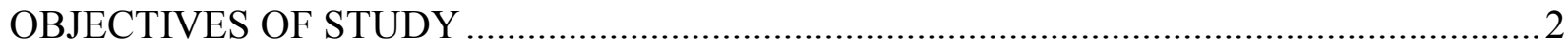

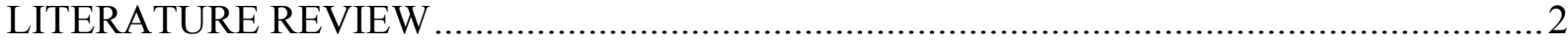

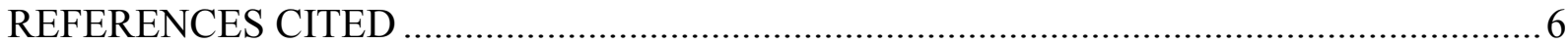

CHAPTER 2: VISUAL AND OLFACTORY PREFERENCE OF HARMONIA AXYRIDIS

PALLAS (COLEOPTERA: COCCINELLIDAE) ADULTS TO VARIOUS FLOWERING

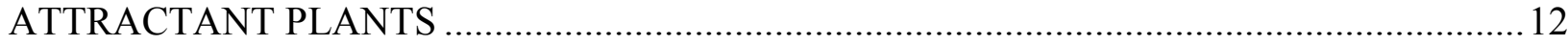

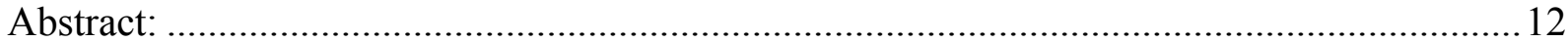

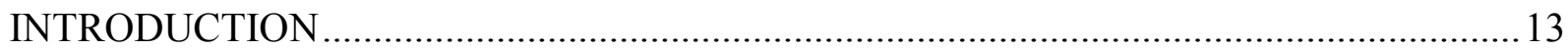

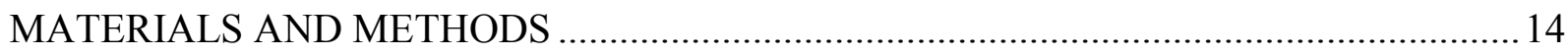

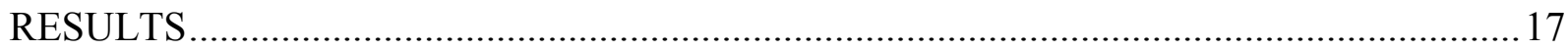

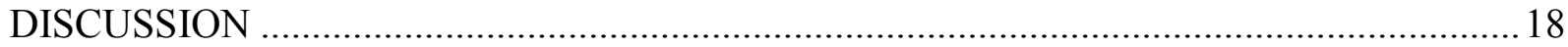

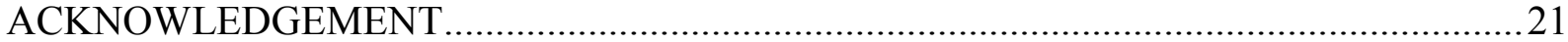

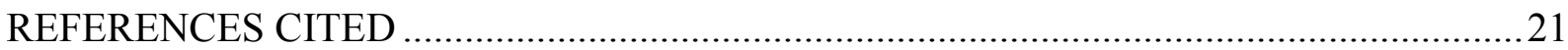

CHAPTER 3: EFFECT OF WITHIN PLANT DISTRIBUTION AND SIZE OF MEALYBUG

(PREY) ON SEARCHING BEHAVIOR OF CRYPTOLAEMUS MONTROUZIERI

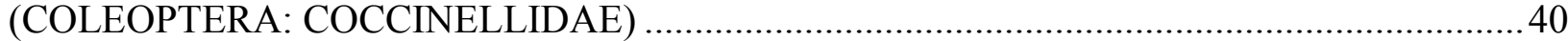

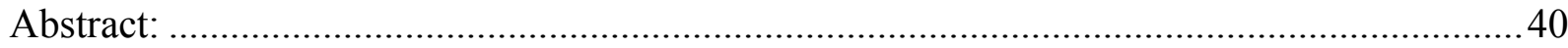

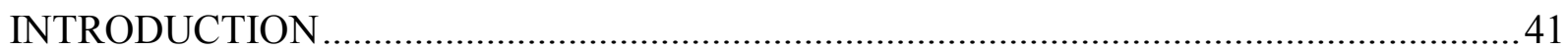

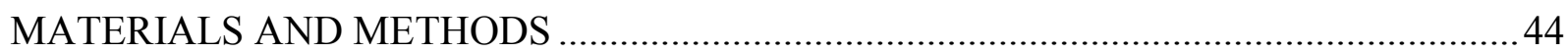

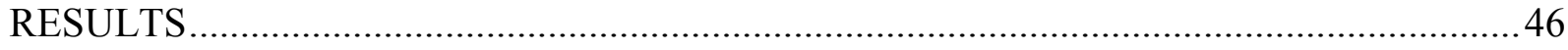

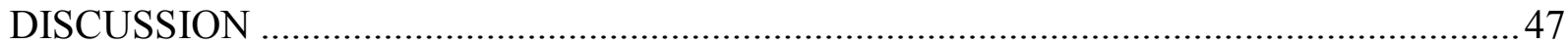

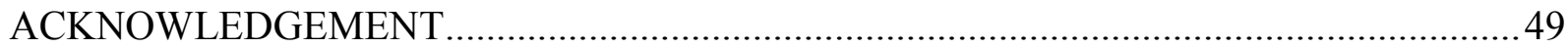

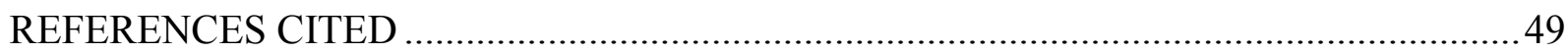

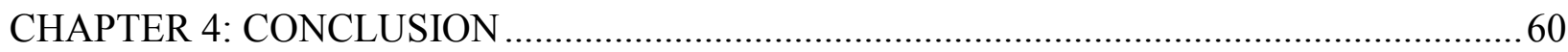

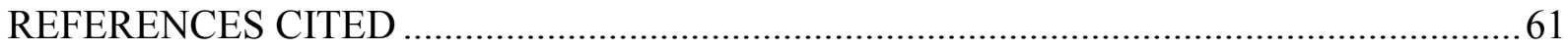




\section{LIST OF TABLES}

Chapter 2 Visual and olfactory preference of Harmonia axyridis Pallas (Coleoptera: Coccinellidae) adult to various flowering attractant plants

Table 1. Preference of $H$. axyridis to ten selected plants with no plant, Chi-square test was used to test the preference.

Table 2. Average $( \pm \mathrm{SE})$ number of male, female and combined of Harmonia axyridis found on six different colors ........................................................ 27

Chapter 3 Effect of within plant distribution and sizes of mealybug (prey) on searching behaviour of Cryptolaemus montrouzieri (Coleoptera; Coccinellidae)

Table 1. Average ( $\pm \mathrm{SE}$ ) number of $P$. longispinus on the top and bottom part of plants with three different heights.

Table 2. Searching, handling and cleaning time of $C$. montrouzieri adults on different plant height at two different releasing locations ................................ 55

Table 3. Handling and cleaning time of $C$. montrouzieri adult feeding on different sizes of mealybug 56 


\section{LIST OF FIGURES}

Chapter 2 Visual and olfactory preference of Harmonia axyridis Pallas (Coleoptera:

Coccinellidae) adult to various flowering attractant plants

Figure 1. Y-tube olfactory meter used for choice test examining the preference of H. axyridis in response to two compared plants. ................................................. 28

Figure 2. Rectangle box used for visual test examining the preference of $\mathrm{H}$. axyridis in response to six different colors (yellow, green, blue, orange, red and white).

Figure 3. Preference of male and female $\mathrm{H}$. axyridis to bugleweed vs. dandelion Chi-square test was used to test the preference. 30

Figure 4. Preference of male and female H. axyridis to yarrow vs marigold. Chisquare test was used to test the preference. 31

Figure 5. Preference of male and female $\mathrm{H}$. axyridis to dill vs butterfly weed. Chi-square test was used to test the preference. 32

Figure 6: Preference of male and female H. axyridis to morning glory vs goldenrod. Chi-square test was used to test the preference. 33

Figure 7: Preference of male and female H. axyridis to tansy vs sunflower. Chisquare test was used to test the preference.

Figure 8: Preference of male and female H. axyridis to sunflower vs bugleweed. Chi-square test was used to test the preference. 35

Figure 9: Preference of male and female $\mathrm{H}$. axyridis to sunflower vs yarrow. Chisquare test was used to test the preference. 36

Figure 10: Preference of male and female $\mathrm{H}$. axyridis to sunflower vs dandelion. Chi-square test was used to test the preference 37

Figure 11: Preference of male and female H. axyridis to sunflower vs marigold. Chi-square test was used to test the preference. 38

Figure 12: Preference of male and female H. axyridis to sunflower vs marigold. Chi-square test was used to test the preference. 39

Chapter 3 Effect of within plant distribution and sizes of mealybug (prey) on searching behaviour of Cryptolaemus montrouzieri (Coleoptera; Coccinellidae)

Figure 1: The behaviour of $\mathrm{C}$. montrouzieri in a 3-way food preference choice test between three stages of $\mathrm{P}$. longispinus: 1st instar $(0.3 \mathrm{~mm})$, 2nd instar $(1.3$ $\mathrm{mm})$ and adult $(3 \mathrm{~mm})$.

Figure 2: Preference of C. montrouzier to stages of P. longispinus: 1st instar $(0.3 \mathrm{~mm}), 2 \mathrm{nd}$ instar $(1.3 \mathrm{~mm})$ and adult $(3 \mathrm{~mm})$. 58 


\section{CHAPTER 1: INTRODUCTION \\ THESIS ORGANIZATION}

This thesis is organized into four chapters. Chapter 1 is a general introduction to the project and a literature review. Chapter 2 discusses the screening and selecting of plant odor and colors that potentially attract Harmonia axyridis Pallas (Coleoptera: Coccinellidae). Chapter 3 addresses within-plant distribution of Pseudococcus longispinus (Targioni-Tozzetti) (Hemiptera: Pseudococcidae), quantifies the searching and handling time, and determines preference of Cryptolaemus montrouzieri Mulsant (Coleoptera: Coccinellidae) to sizes of P. longispinus. Chapter 4 provides a general conclusion for this study. This thesis was prepared according to the publication guidelines established by the Entomological Society of America.

\section{GENERAL INTRODUCTION}

Effective pest management techniques will go a long way in striking a balance between meeting the demands of food supply for the growing world population and the social concerns of the effects of pesticides on humans and the environment at large. Pest management is the act of controlling pest populations which are considered to be a major barrier in crop production by reducing yields. Many methods have been adopted in controlling pest populations, but the most common method still is the use of pesticides. Pesticides, specifically insecticides, are chemicals that injure or kill insects; however spraying pesticides has a significant negative impact on humans and the environment. These may include serious human health risks, large-scale destruction of non target organisms and plants, and severe environmental impacts within the ecosystem. Additionally, pest populations have often developed resistance to the commonly used pesticides (Saxena 1982, Swezey and Salamanca 1987), and hence there are needs for alternative control strategies. A main alternative pest control tactic to pesticides is biological control, the use of natural enemies; biological control is one of the most important environmentally-friendly pest 
management strategies. In this thesis, ecological behavioral of two major natural enemies (i.e. $H$. axyridis and C. montrouzieri) was investigated to improve biological control of two major horticultural pests, aphids and mealybugs.

\section{OBJECTIVES OF STUDY}

The goal of this study was to investigate the potential of using two generalist natural enemies, $H$. axyridis and C. montrouzieri as biological control agents. The objectives of this research were:

1. To develop a method to attract $H$. axyridis using companion planting by screening and selecting plants whose odor and color attract $H$. axyridis (Chapter 2).

2. To determine the searching and handling time and preference of $C$. montrouzieri using P. longispinus as prey at various plant heights (Chapter 3).

\section{LITERATURE REVIEW}

Life history of $\boldsymbol{H}$. axyridis: The multi-colored Asian lady beetle, Harmonia axyridis Pallas, is an introduced biological control agent native to western Asia. It was first introduced into North America in 1916 and 1982 (Colunga-Garcia and Gage 1998) and the intention was to introduce a new beneficial predator. Harmonia axyridis is a highly voracious predator on a variety of insect pests, including aphids in food crops, trees and landscape plantings (Hukusima and Kamei 1970). In the eastern United States, H. axyridis has been used to control aphids in pecan orchards and has spread throughout the east coast. $H$. axyridis has become the dominant lady beetle species in many parts of the United States. Despite these successes in agroecosystems, H. axyridis has received more attention because it is a problem in late summer, when adults feed on ripening fruit in some geographic locations (Koch et al. 2004), and in autumn, when large numbers alight on buildings then move into interior spaces, looking for dark, protected fissures to settle for 
the winter.

H. axyridis has four distinct life stages: egg, larva, pupa and adult (Wang 1986, Hodek 1973). Adults of $H$. axyridis are oval, about $6 \mathrm{~mm}(1 / 4 \mathrm{inch})$ long and range in color from yellow to orange to red, with or without black spots on the wing covers (LaMana and Miller 1996); the number of spots varies drastically, ranging from zero to at least twenty. The head is usually concealed from above and the white pronotum generally has a black "M"-like shape, which is a key feature for species identification (Chapin and Brou 1991). Harmonia axyridis larvae are elongate, flattened and covered with minute spines (Chapin 1965, Kuznetsov 1997, Sasaji 1971). The larvae can rapidly move around leaves and branches, where they eat aphids and other softbodied insects. The pupa is orange with black spots and similar in size and shape to the adult. Eggs are yellow, oval shaped and laid upright in clusters of about 20, usually on the undersides of leaves.

Harmonia axyridis is bivoltine and overwinters as an adult in cracks and crevices in late October (Kidd et al. 1995, LaMana and Miller 1996). Harmonia axyridis adults begin laying eggs on host plants in early spring. Eggs hatch in about three to five days, and larvae begin searching on plants for aphids and other soft-bodied arthropods on which to feed (Osawa 2000, Sakurai et al. 1992); adults and larvae typically feed upon the same prey. Larvae molt four times to become pupae and pupation lasts five to six days until adults emerge (El-sebaey and ElGantiry 1999). Adults typically live 30 to 90 days depending on temperature (El-Sebaey and ElGantiry 1999, He et al. 1994, Soares et al. 2001). Development from egg to adult requires 267.3 degree days above a lower developmental threshold of $11.2^{\circ} \mathrm{C}$ in the United States (LaMana and Miller 1998). In October and November adults congregate to find overwintering sites and they attempt to return to their outdoor habitat in February and March. Generally adults mate before 
dispersing from overwintering sites (LaMana and Miller 1996). Sexual activity of $H$. axyridis and other Coccinellidae was reviewed by Hodek and Ceryngier 2000.

In the United States, $H$. axyridis has been used for biological control in pecans (Tedders and Schaefer 1994) and red pines (McClure 1987). Harmonia axyridis contributes more to biological control of the pecan aphid complex in the southeastern United States than in the southwestern United States (Rice et al. 1998, Tedders and Schaefer 1994). In apple orchards, $H$. axyridis provides effective biological control of Aphis spiraecola (Brown and Miller 1998). The biological control of several citrus pests may also be benefiting from the establishment of $H$. axyridis (Michaud 1999, Michaud 2000, Michaud 2001a, Michaud 2001b, Michaud 2002, Stuart et al. 2002). In sweet corn, H. axyridis controls Ostrinia nubilalis eggs and Rhopalosiphum maidis (Musser and Shelton 2003). Harmonia axyridis has also been documented in alfalfa (Buntin and Bouton 1997, Colunga-Garcia and Gage 1998), cotton (Wells et al. 2001), tobacco (Wells and McPherson 1999), and winter wheat (Colunga-Garcia and Gage 1998) as a major biological control agent.

Life history of Cryptolaemus montrouzieri: The mealybug destroyer, Cryptolaemus montrouzieri Mulsant (Coleoptera: Coccinellidae), was imported into the United States in 1891 from Australia to control citrus mealybug in California (Sadof 1995). Cryptolaemus montrouzieri is a small (about 3-4 mm long), dark brown lady beetle with a tan to orange head. The larvae grow to $1.3 \mathrm{~cm}$ in length and have woolly appendages of wax, which makes them resemble mealybugs. Cryptolaemus montrouzieri eggs are laid among the cottony egg sack of adult female mealybugs. Eggs hatch into larvae in about 5 days at $27^{\circ} \mathrm{C}\left(80^{\circ} \mathrm{F}\right)$ and the three larval stages last from 12-17 days. The larvae feed on mealybug eggs, young crawlers, and the honeydew produced by mealybugs (Yigit and Canhilal 1998). Cryptolaemus montrouzieri pupates in 
sheltered places on stems or on greenhouse structures. Adults emerge after 7-10 days and live four months. Four days after emerging, adult females begin to lay eggs, and total number of eggs laid in a lifetime may be as many as 400 (Sadof 1995).

Life history and management of $\boldsymbol{P}$. longispinus: The long-tailed mealybug Pseudococcus longispinus (Targioni-Tozzetti), (Hemiptera: Pseudococcidae), eggs are yellow at first and get dark before hatching (McKenzie 1967). The eggs may hatch as soon as they are laid, suggesting that young are born rather than hatching. Females lay 20 to 240 eggs under lab conditions (Furness 1976). The lavae are flattened, oval and light yellow with smooth bodies. Soon after beginning to feed, they exude a white, waxy covering over their bodies to camouflage themselves (Metcalf and Flint 1939). The female body is oval and covered with waxy filaments (McKenzie 1967) and they live 2 to 3 months. The males are tiny and winged, necessary for reproduction but live only a few days (Metcalf \& Flint 1939).

Control of $P$. longispinus with insecticides is difficult because they hide in bark crevices and other inaccessible places and secrete thick layers of protective wax (Joyce et al., 2001). Cryptolaemus montrouzieri is a natural enemy of mealybug in both the larval and adult stages; a single larva may consume up to 250 small mealybugs. They are most effective when mealybug populations are high, and repeated releases may be necessary if mealybug populations are low (Sadof 1995). Although adults and young larvae prefer to feed on mealybug eggs, older larvae will attack any mealybug stage.

Preference test (choice test) for coccinellid beetles: In the last several decades, response of coccinellid beetles to different odors was investigated in a Y-tube olfactometer as described by Souissi et al.1998. Dicke et al. (1990) showed that mealybug-infested plants, damaged plants, and unparasitized mealybugs are significantly attractive to Exochomus 
flaviventris Mader (Coleoptera: Coccinellidae). The attraction of E. flaviventris resulted from an increased production of volatiles or a change in the volatile blend. Bahlai et al. 2008 examined the roles of visual and olfactory cues from selected components of a hedgerow ecosystem in the foraging of $H$. axyridis. Olfactory bioassays were performed in a Y-tube olfactometer and they tested the response of $H$. axyridis to the odor of buckthorn leaves (Rhamnus cathartica $\mathrm{L}$ ) and apple leaves (Malus domestica Borkh.). They found no differences between the numbers of beetles moving toward the odor of buckthorn artificially infested with A. glycines and uninfested buckthorn, but $H$. axyridis preferred naturally infested buckthorn over uninfested buckthorn. The results of this study provided information regarding the cues used in foraging of $H$. axyridis.

\section{REFERENCES CITED}

Bahlai, C. A., J. A. Welsman, E. C. Macleod, A. W. Schaafsma, R. H. Hallett, and

M. K. Sears. 2008. Role of visual and olfactory cues from agricultural hedgerows in the orientation behavior of multicolored Asian lady beetle (Coleoptera: Coccinellidae). Environ. Entomol. 37: 973-979.

Brown, M. W., and S. S. Miller. 1998. Coccinellidae (Coleoptera) in apple orchards of eastern West Virginia and the impact of invasion by Harmonia axyridis. Entomol. News 109: $136-142$.

Buntin, G. D., and J. H. Bouton. 1997. Aphid (Homoptera: Aphididae) management in alfalfa by spring grazing cattle. J. Entomol. Sci. 32: 332-342.

Chapin, E. A. 1965. Coccinellidae: Insect of micronesia. Bernice P. Bishop Museum. 66 pp. Honolulu, Hawaii 
Chapin, J. B., and V. A. Brou. 1991. Harmonia axyridis (Pallas), the third species of the genus to be found in the United States (Coleoptera: Coccinellidae). Proc. Entomol. Soc. Wash. 93: 630-635.

Colunga-Garcia, M., and S. H. Gage. 1998. Arrival, establishment, and habitat use of the multicolored Asian lady beetle (Coleoptera: Coccinellidae) in a Michigan landscape. Environ. Entomol. 27: 1574-1580.

Dicke, M., M. W. Sabelis, J. Takabayashi, J. Bruin, and M. A. Posthumus. 1990. Plant strategies of manipulating predator-prey interactions through allelochemicals: Prospects for application in pest control. J. Chem. Ecol. 16: 3091-3118.

El-Sebaey, I. I. A., and A. M. El-Gantiry. 1999. Biological aspects and description of different stages of Harmonia axyridis (Pallas) (Coleoptera: Coccinellidae). Bull. Agric. Cairo Univ. 50: 87-97.

Furness, G. O. 1976. The dispersal, age-structure and natural enemies of the long-tailed mealybug, Pseudococcus longispinus (Targioni-Tozzetti), in relation to sampling and control. J. Aust. Zool. 24: 237-47.

He, J. L., E. P. Ma, Y. C. Shen, W. L. Chen, and X. Q. Sun. 1994. Observations of the biological characteristics of Harmonia axyridis (Pallas) (Coleoptera: Coccinellidae). J. Shanghai Agric. College 12: 119-124.

Hodek, I. 1973. Life history and biological properties, pp.70-73. In Hodek I. (ed), Biology of Coccinellidae. Hauge, Holand.

Hodek, I., and P. Ceryngier. 2000. Sexual activity in Coccinellidae (Coleoptera). J. Eur. Entomol. 97: 449-456. 
Hukusima, S., and M. Kamei. 1970. Effects of various species of aphids as food on development, fecundity and longevity of Harmonia axyridis Pallas (coleoptera: Coccinellidae). Res. Bull. Fac. Agric. Gifu Univ. 29: 53-66.

Joyce, A. L., M. S. Hoddle, T.S. Bellows, and D. Gonzaldz. 2001. Oviposition behaviour of Coecidoxenoides peregrinus, a parasitoid of Planococcus ficus. Entomol. Exp. Appl. 98: 49-57.

Kidd, K. A., C. A. Nalepa, E. R. Day, and M. G. Waldvogel. 1995. Distribution of Harmonia axyridis (Pallas) (Coleoptera: Coccinellidae) in North Carolina and Virginia. Proc. Entomol. Soc. Wash. 97: 729-731.

Koch, R. L., E. C. Burkness, S. J. Wold Burkness, and W. D. Hutchison. 2004. Phytophagous preferences of the multicolored Asian lady beetle (Coleoptera: Coccinellidae) for autumn-ripening fruit. J. Econ. Entomol. 97: 539-544.

Kuznetsov, V. N. 1997. Lady beetle of Russian far east, Memoir Seis ed, CSE. Sandhill crane press, Gainesville, FL.

LaMana, M. L., and J. C. Miller 1996. Field Observations on Harmonia axyridis Pallas (Coleoptera: Coccinellidae) in Oregon. Biocontrol 6: 232-237.

LaMana, M. L, and J. C. Miller. 1998. Temperature-dependent development in an Oregon population of Harmonia axyridis (Coleoptera: Coccinellidae). Environ. Entomol. 27: 1001-1005.

Metcalf, C. L. and W. P. Flint. 1939. Destructive and useful insects, $2^{\text {nd }}$ ed, McGrawHill book company, NY. pp. 981.

Mckenzie, H. L. 1997. Mealybugs of California University of California press. Berkeley, CA. 
McClure, M. S. 1987. Potential of the Asian predator, Harmonia axyridis Pallas (Coleoptera: Coccinellidae), to control Matsucoccus resinosae Bean and Godwin (Homoptera: Margarodidae) in the Unted States. Environ. Entomol.16: 224-230.

Michaud, J. P. 1999. Sources of mortality in colonies of brown citrus aphid, Toxoptera citricida. Biocontrol 44: 347-367.

Michaud, J. P. 2000. Development and reproduction of ladybeetles (Coleoptera: Coccinellidae) on the citrus aphids Aphis spiraecola Patch and Toxoptera citricida (Kirkaldy) (Homoptera: Aphidae). Biocontrol 18: 287-297.

Michaud, J. P. 2001a. Evaluation of green lacewings, Chrysoperla plorabunda (Fitch) (Neuroptera: Chrysopidae), for augmentative release against Toxoptera citricida (Homoptera: Aphididae) in citrus. J. Appl. Entomol. 125: 383-388.

Michaud, J. P. 2001b. Numerical response of Olla V-Nigrum (Coleoptera: Coccinellidae) to infestations of Asian citrus psyllid, (Hemiptera: Psyllidae) in Florida. Fl. Entomol. 84: 608-612.

Michaud, J. P. 2002. Biological control of Asian citrus psyllid, Diaphorina citri (Hemiptera: Psyllidae) in Florida: a preliminary report. Entomol. News 113: 216-222.

Musser, F. R, and A. M. Shelton. 2003. Bt sweet corn and selective insecticides: impacts on pests and predators. J. Econ. Entomol. 96: 71-80.

Osawa, N. 2000. Population field studies on the aphidophagous ladybird beetle Harmonia axyridis (Coleoptera: Coccinellidae): resource tracking and population characteristics. Pop. Ecol. 42: 115-127.

Rice, N. R., M. W. Smith, R. D. Eikenbary, D. Arnold, W. L. Tedders, B. Wood, B. S. Landgraf, G. G. Taylor, and G. E. Barlow. 1998. Assessment of legume and 
nonlegume ground covers on Coleoptera: Coccinellidae density for low-input pecan management. Am. J. Alter. Agric. 13: 111-123.

Sadof, C. 1995. Know Your Friends: Mealybug Destroyer. www.oisat.org/control_methods/natural_enemies/predators/mealybug_destroyer.html.

Sakurai, H., T. Kawai, and S. Takeda. 1992. Physiological changes related to diapause of the lady beetle, Harmonia axyridis (Coleoptera: Coccinellidae). Appl. Entomol. Zool. 27: $479-487$.

Sasaji, H. 1971. Fauna Japonica, Coccinellidae (Insecta: Coleoptera). Acad. Press. Tokyo, Japan.

Saxena, R. C. 1982. Colonization of rice fields by Nilaparvata lugens (Stal) and its control using a trap crop. Crop Prot. 1:191-98.

Soares, A. O., D. Coderre, and H. Schanderl. 2001. Fitness of two phenotypes of Harmonia axyridis (Coleoptera: Coccinellidae). Eur. J. Entomol. 98: 287-293.

Souissi, R., J. P. Nenon, and U. B. LeR. 1998. Olfactory responses of the parasitoid Apoanagyruslopezi to odor of plants, mealybugs and plant-mealybug complexes. J. Chem. Ecol. 24: 37-48.

Stuart, R. J., J. P. Michaud, L. Olsen, and C. W. McCoy. 2002. Lady beetles as potential predators of the root weevil Diaprepes abbreviates (Coleoptera: Curculionidae) in Florida citrus. Fl. Entomol. 85: 409-416.

Swezey, S. L., and M. L. Salamanca, 1987. Susceptibility of the boll weevil (Coleoptera: Curculionidae) to methyl parathion in Nicaragua. J. Econ. Entomol. 80:358-61. 
Tedders, W. L., and P. W. Schaefer. 1994. Release and establishment of Harmonia axyridis (Coleoptera: Coccinellidae) in the southeastern United States. Entomol. News 105: 228243.

Wang, L.Y. 1986. Mass rearing and utilization in biological control of the lady beetle Leis axyridis (Pallas). Acta Entomol. Sinica 29: 104.

Wells, M. L., and R. M. McPherson. 1999. Population dynamics of three coccinellids in fluecured tobacco and functional response of Hippodamia convergens (Coleoptera: Coccinellidae) feeding on tobacco aphids (Homoptera: Aphididae). Environ. Entomol. 28: $768-773$.

Wells, M. L., R. M. McPherson, J. R. Ruberson, and G. A. Herzog. 2001. Coccinelids in cotton: population response to pesticide application and feeding response to cotton aphids (Homoptera: Aphididae). Environ. Entomol. 30: 785-793.

Yigit, A., and R. Canbilal. 1998. Introduction into East Mediterranean region of cold-tolerant ecotypcs of the Citrus mealybug's predator Cryptolaemus montrouzieri Mulsant (Coleoptera: Coccinellidae), some biological properties and their adaptation to the region. Bull. Plant Prot. 38: $23-41$. 


\title{
CHAPTER 2: VISUAL AND OLFACTORY PREFERENCE OF HARMONIA AXYRIDIS PALLAS (COLEOPTERA: COCCINELLIDAE) ADULTS TO VARIOUS FLOWERING ATTRACTANT PLANTS
}

\begin{abstract}
Using natural enemies to suppress pest population within cropping systems, suitable habitat must be provided. This study was conducted to determine if Harmonia axyridis Pallas (Coleoptera: Coccinellidae) could be attracted into cropping areas using companion plants with different olfactory and visual cues. Ten potential plants that can attract and provide $H$. axyridis with nectar and pollen were selected for a preference test. These plants included dill (Anethum graveolens), yarrow (Achillea spp.), butterfly weed (Asclepias tuberosa), dandelion (Taraxacum officinale), bugleweed (Ajuga reptans), marigold (Tagetes tenuifolia), tansy (Tanacetum vulgare), goldenrod (Solidago spp.), morninglory (Ipomoea spp.), and sunflower (Helianthus annuиs). The result of the olfactory preference test showed that there was significant difference in the plant preference by $H$. axyridis; sunflower and dill were the most preferred attractant plants. In a visual preference test, $H$. axyridis preferred yellow to other colors. This study suggests that the odor of certain companion plants and the color of the plants (olfactory and visual cues) could assist in the use of biological control by attracting high populations of $H$. axyridis and keeping them within the cropping area.
\end{abstract}

Keywords: choice test, visual test, preference, $H$. axyridis 
The multi-colored Asian lady beetle, Harmonia axyridis Pallas (Coleoptera: Coccinellidae), is an introduced biological control agent to the U.S.A. (Chapin and Brou 1991). H. axyridis is native to East Asia and multiple introductions into North America were made in 1916 and 1982 (Koch 2003, Colunga-Garcia and Gage 1998). Since the first introduction, $H$. axyridis has become a dominant lady beetle species in many parts of North America (Tedders and Schaefer 1994, LaMana and Miller 1996, Colunga-Garcia and Gage 1998). Currently, $H$. axyridis is found in various habitats including meadows, semi-natural areas, nurseries, orchards, vegetable gardens and crop fields (Koch 2003,). H. axyridis generally moves among such habitats by using olfactory and visual cues of aphid host plants (Koch 2003, Nalepa et al. 2000).

Natural enemies can be spatially relocated by providing habitat for them (Helenius 1998, Landis et al. 2000). A farm management technique used to enhance the presence and abundance of beneficial insects (e.g. natural enemies and pollinators) by manipulating the agricultural ecosystem is referred to as farmscaping, a whole-farm ecological approach to farm management (Dufour 2000). Farmscapes can provide food resources and habitats required by beneficial insects with the objective of increasing their populations on the farm (Pickett and Bugg 1998). Previous studies showed that the addition of companion plants providing nectar and pollen near crops enhanced biological control (Seagraves and Yeargan 2006). A few studies found that sown weed strips within cropped areas increased populations and activities of natural enemies in crops (Wyss 1995, Nentwig 1998, Schoenig et al. 1998, Wratten et al. 1998). Jones and Gillett (2005) found that sunflowers attracted numerous beneficial insects and Dufour (2000) listed many flowering plants that could attract and provide supplemental food source for beneficial insects. These previous studies indicated the potential of farmscaping using companion plants to attract natural enemies. 
Although many natural enemies have been used to suppress pest populations in various agroecosystem, there have been two major barriers to the adoption of the strategy by farmers. First, specialist natural enemies (e.g. parasitic wasps) are widely used for biological pest control. However, they are frequently unavailable and expensive to growers due to temporal shortage. Second, no good methods for growers to utilize generalist natural enemies (e.g. soldier bugs and lady beetles) have been developed. In fact, many generalist natural enemies that can potentially control many insect pests already reside in agricultural ecosystems during the growing season. One way to take advantage of such generalist natural enemies existing on the farm is using farmscapes to attract them into the area where target pests are aggregated and cause damage on crops. H. axyridis is a generalist predator of a variety of pests including aphids (Koch 2003) and European corn borer eggs (Musser and Shelton 2003). Our observation and previous studies (Hukusima and Kamei 1970, Park and Obrycki 2004) implied that $H$. axyridis resided both inside and outside of cropping areas on the farm, but populations were generally not high in the cropping area in certain periods during the growing season. Many flowering plants have been listed to attract beneficial insects (Dufour 2000) and previous studies showed that $H$. axyridis responded to plant cues (Koch 2003, Bahlai et al. 2008, Berkvens et al. 2008).

This study was conducted to test ten potential companion plants that can be used for farmscapes to attract $H$. axyridis into cropping areas based on olfactory and visual response of $H$. axyridis to the companion plants. This study involved a series of laboratory choice tests to determine suitable plants that attract $H$. axyridis.

\section{MATERIALS AND METHODS}

Experimental insects and plants. This study involved a series of laboratory experiments to determine plant odors and colors that attract $H$. axyridis using choice tests. Harmonia axyridis 
adults were collected in Morgantown, West Virginia, United States between April and June 2008 and maintained in the entomology laboratory at West Virginia University (Morgantown, West Virginia, United States) and fed with aphids (Aphis spp.). Ten plants that can attract and provide beneficial insects with nectar and pollen were selected. These plants included dill (Anethum graveolens), tansy (Tanacetum vulgare), goldenrod (Solidago spp.), sunflower (Helianthus annuus), yarrow (Achillea spp.), butterfly weed (Asclepias tuberosa), morninglory (Ipomoea spp.), dandelion (Taraxacum officinale), bugleweed (Ajuga reptans), and marigold (Tagetes tenuifolia). These plants were chosen because they bloom when $H$. axyridis are active.

Olfactory meter setup. The response of $H$. axyridis to different plant odors was investigated with a Y-tube olfactometer as described by (Souissi et al. 1998, Takabayashi and Dicke, 1992). It consisted of a Y-shaped 2.5-cm-diameter glass tube. The base and the two arms of the Y-tube measured 28 and $13 \mathrm{~cm}$ long, respectively (Fig 1). Each arm was connected to a flowmeter which gives the same amount of air to the two arms and an odor source container made of a glass cylinder $(25 \mathrm{~cm}$ in diameter and $40 \mathrm{~cm}$ high), which was large enough to hold the plant. The air circulated in each olfactometer arm was 40 psi. Female and male predators were able to walk upwind toward the arms of the tube and sometimes performed short flight attempts.

Experiment 1: Single plant olfactory preference test. A laboratory experiment was conducted to select suitable plants that attract $H$. axyridis adults based on olfactory preference. Male and female $H$. axyridis were separated into a petri dish and starved for $24 \mathrm{~h}$ before their use in the experiments. Each plant (flowering part) was field collected at bloom time and choice tests were carried out using the Y-tube olfactory meter. One flower was placed in one of the arms with no plant in the other arm (Fig 1). One adult beetle was introduced at the start point in the Y-tube 
olfactory meter. The direction of movement toward the two arms of the olfactory meter was determined when a predator reached the far end (finish line) of one of the arms. This was repeated ten times with ten different adult beetles and the results of each trial were tested for statistical differences using a chi-square test (Sokal and Rohlf 1998).

Experiment 2: Two plants olfactory comparison test. The same choice test was conducted as described in experiment 1, with the exception of testing two different plants using the olfactory meter. The following pairs of flowers were compared:

1. bugleweed versus dandelion

2. yarrow versus marigold

3. dill versus butterfly weed

4. morning glory versus goldenrod

5. tansy versus sunflower

6. sunflower versus marigold

7. sunflower versus dandelion

8. sunflower versus yarrow

9. sunflower versus bugleweed

10. sunflower versus dill

One beetle was introduced at the start point in the Y-tube olfactory meter and its choice to a plant was recorded. This test was repeated ten times with male and female $H$. axyridis separately. The results of each trial were analyzed for significance by a chi-square test (Sokal and Rohlf 1998).

Experiment 3: Visual preference test. A field study was conducted to test visual preference of $H$. axyridis adults. Six different colored rectangle cardboard papers measuring 5.6 
inches by 5.2 inches were painted with tanglefoot (Tanglefoot Company, Grand Rapids, MI) and randomly arranged in a rectangle form on a Plexiglas frame (Fig. 2). These colors included yellow (R: 189, G: 166, B: 44), Blue (R: 89, G: 123, B: 178), Green (R: 50, G: 132, B: 88), Red (R: 206, G: 50, B: 71), Orange (R: 219, G: 76, B: 40) and white (R: 183, G: 188, B: 196). Ten $H$. axyridis adults were released in the center of the box to see which color would attract them. The number of adults on each color cardboard was recorded 30 minutes after release. This experiment was replicated ten times with different insects, and preference of $H$. axyridis to different colors was analyzed with ANOVA (SAS Institute 2008).

\section{RESULTS}

Experiment 1: Single plant olfactory preference test. When two choices (plant vs. no plant) were tested for preference by $H$. axyridis adults, they exhibited a significant $(P<0.05)$ preference for dandelion, bugleweed, marigold, butterfly weed, dill, and sunflower (Table 1). However, there were no significant preferences for yarrow, morninglory, goldenrod and tansy, although these plants were also known as potential attractant plants in the literature (Dufour 2000).

Experiment 2: Two plants olfactory comparison test. Harmonia axyridis adults exhibited a significant preference for bugleweed over dandelion $\left(X^{2}=3.2 ; \mathrm{df}=1 ; P=0.0736\right)$, however, there was no difference between males and females attracted to bugleweed (Fig. 3). $H$. axyridis adults exhibited a significant statistics preference for marigold over yarrow $\left(X^{2}=5.0 ; \mathrm{df}\right.$ $=1 ; P=0.0253$ ), with a significant difference between males and females attracted to marigold (Fig. 4). Lady beetles exhibited a significant preference for dill over butterfly weed $\left(X^{2}=9.8\right.$; df $=1 ; P=0.0017)$, and a significant statistics difference was found between males and females $H$. axyridis attracted to dill plant (Fig. 5). H. axyridis adults did not exhibit a significant preference 
for morning glory over goldenrod $\left(X^{2}=1.8 ; \mathrm{df}=1 ; P=0.1797\right)$, although there was a significant statistics difference between males and females attracted to goldenrod (Fig. 6). H. axyridis adults exhibited highly significant preference for sunflower over tansy $\left(X^{2}=12.8 ; \mathrm{df}=1 ; P=0.0003\right)$ and there was a significant statistics difference between males and females attracted to sunflower (Fig. 7). H. axyridis adults exhibited extremely significant preference for sunflower over yarrow $\left(X^{2}=9.8 ; \mathrm{df}=1 ; P=0.0017\right)$, however, there was no significant statistics difference between males and females attracted to sunflower (Fig. 8). H. axyridis adults exhibited highly significant preference for sunflower over bugleweed $\left(X^{2}=12.8 ; \mathrm{df}=1 ; P=0.0003\right)$, however, there was no significant statistics difference between males and females attracted to sunflower (Fig. 9). $H$. axyridis adults exhibited extremely significant preference for sunflower over dandelion $\left(X^{2}=5.0\right.$; $\mathrm{df}=1 ; P=0.0253)$, and there was a significant statistics difference between males and females attracted to sunflower (Fig.10). H. axyridis adults exhibited a highly significant preference for sunflower over marigold $\left(X^{2}=7.2 ; \mathrm{df}=1 ; P=0.0073\right)$, however, there was no significant statistics difference between males and females attracted to sunflower (Fig. 11). H. axyridis adults exhibited extremely significant preference for sunflower over dill $\left(X^{2}=7.2 ; \mathrm{df}=1 ; P=\right.$ 0.0073), and there was a significant statistics difference between males and females attracted to sunflower (Fig.12). Because the flowering time of each plant is different throughout the year (Table 1), suitable companion plants can be selected based on when $H$. axyridis adults are needed for aphid control. For example, bugleweed can be used early in the year and goldenrod late in the year.

Experiment 3: Visual preference test. Among the six colors that were tested in this research, (Yellow, blue, red, orange, green and white), H. axyridis adults exhibited a significant preference for for yellow over others color $(F=62.25$; $\mathrm{df}=5,59 ; P<0.0001)$ (Table 2$)$. We 
found that the number of $H$. axyridis females found on yellow was significantly higher $(F=$ 19.92; df $=5,59 ; P<0.0001$ ) (Table 2). However, $H$. axyridis male were not significantly attracted to yellow $(F=9.06 ; \mathrm{df}=5,59 ; P<0.0001)($ Table 2$)$.

\section{DISCUSSION}

Compared to specialist natural enemies, generalist natural enemies can feed on a broad range of prey species in multiple genera, which is a major advantage of using them to control multiple pest insects in cropping systems. For example, soldier bugs feed on more than 75 insect pests including Colorado potato beetles, Mexican bean beetles, earworms, cutworms, cucumber beetles, armyworms, flea beetles, weevils, and stink bugs (McPherson 1980). Lady beetles can feed on aphids, mealybugs, scale insects, and eggs of moths (Dufour 2000, Park and Obrycki 2004). Another advantage of using generalist natural enemies is that they commonly reside on the farm throughout the growing season and can utilize plants as energy sources for reproduction and survival (Jones and Gillett 2005). Lady beetles can inhabit a farm even during scarcity of prey insects by feeding on pollen, nectar, or plant sap (Landis et al. 2005, Spellman et al. 2006, Fiedler and Landis 2007). Companion plants can provide such food and shelter for natural enemies as well as stimulate relocations of natural enemies into the cropping areas where they can control insect pests (Johanowicz and Mitchell 2000, Mensah 1999, Nentwig 1998, Schoenig et al. 1998, Wratten et al. 1998, Rodenhouse et al. 1992).

Olfactory cues of companion plants could play an important role in attracting natural enemies into cropping areas. Some natural enemies use plant volatiles to search for prey (Schaller and Nentwig 2000) and such chemicals can provide an adaptive advantage to natural enemies by shortening search time required to find prey (Hattingh and Samways 1995). In this study we found that $H$. axyridis were highly attracted to olfactory cues of sunflower, which was 
consistent with field observations by Jones and Gillett (2005) who showed that sunflower plants attracted natural enemies when sunflowers reached a minimum height of $2.4 \mathrm{~cm}$. The results of our study provide evidence that $H$. axyridis adults were highly attracted to volatiles from bugleweed, dill, marigold, sunflower, and goldenrod; volatiles associated with the plants were able to attract $H$. axyridis adults even in the absence of prey although many of these plants are acceptable hosts for aphids.

Visual cues also play important roles in host-finding activity of $H$. axyridis. The result of our study suggested that adult $H$. axyridis could be attracted by color even when scent cues are eliminated. $H$. axyridis exhibited a significant preference for yellow over other colors, which was consistent with field observation by Mondor and Warren (2000) who showed that both male and female $H$. axyridis were attracted to yellow color. This could be related to aphids that are commonly found on plants with yellow flowers. The result of our study showed that blue and red were the least preferred color to $H$. axyridis adults. We also found that both male and female $H$. axyridis showed preferences to different colors (Table 2); some $H$. axyridis males were attracted to orange and red while females were not. Additionally, when $H$. axyridis search for overwintering sites, they are attracted to and land on white or bright, reflective surfaces (Koch 2003, Obata et al. 1986).

Knowledge about how natural enemies utilize both visual and olfactory cues may lead to development of strategies to attract $H$. axyridis populations for aphid biological control (Bahlai et al. 2008). The result of this study provides two important implications for biological control with $H$. axyridis. First, $H$. axyridis pontentially can be spatially relocated to cropping areas by using some companion plants. $H$. axyridis could be attracted by olfactory and visual cues of a few companion plants and yellow color, respectively. In this study, we found that volatiles of 
bugleweed, marigold, butterfly weed, dill, and sunflower attracted $H$. axyridis and these plants with the exception of bugleweed have yellow flowers, indicating that $H$. axyridis adults can be attracted to both visual and chemical cues of the plants. The companion plants can also be used to keep H. axyridis in the cropping area even when there are no aphids, because they can feed on pollen and nectar of the companion plants.

Second, depending on crop species, selective planting of attractant plants can be done to attract $H$. axyridis season long. In this study, we found that five species of flowering plants attracted $H$. axyridis with olfactory cues and those plants can be systematically planted for targeting a series of bloom throughout the season; because the blooming time of each plant is different throughout the year, suitable companion plants can be selected based on when $H$. axyridis adults are needed for aphid control. For example, in addition to sunflower blooming during the middle of the growing season, bugleweed and goldenrod can be used early and late in the growing season, respectively, to attract $H$. axyridis adults.

Future work should examine the response of $H$. axyridis to specific volatiles associated with potential companion plants as well as chemical analyses of the volatiles. Important issues related to aphid control with $H$. axyridis include timing when aphid and $H$. axyridis populations generally first appear, when food sources (nectar and pollen from companion plants) are available and how long they last, and number of plantings and plant species mixes to enhance attraction of $H$. axyridis.

\section{ACKNOWLEDGEMENT}

I wish to thank Vicki Kondo at West Virginia University for helping in seeding the plants that were used for this research and her valuable suggestions. This research was supported by a Faculty Senate Grant and Division of Plant and Soil Science at West Virginia University. 


\section{REFERENCES CITED}

\section{Bahlai, C. A., J. A. Welsman, E. C. Macleod, A. W. Schaafsma, R. H. Hallett, and M. K.}

Sears. 2008. Role of Visual and Olfactory Cues from Agricultural Hedgerows in the Orientation Behavior of Multicolored Asian Lady Beetle (Coleoptera: Coccinellidae). Environ. Entomol. 37: 973-979.

Colunga-Garcia, M. and S.H. Gage 1998. Arrival, establishment, and habitat use of the multicolored Asian lady beetle (Coleoptera: Coccinellidae) in a Michigan landscape. Environ. Entomol. 27: 1574-1580.

Dufour, R. 2000. Farmscaping to enhance biological control. http://attra.ncat.org/attra-pub/farmscape.html.

Hattingh, V., and M. J. Samways. 1995. Visual and olfactory location of biotopes, prey patches, and individual prey by the lady beetle Chilocorus nigritus. Entomol. Exp. Appl. 75: 87-98.

Helenius, J. 1998. Enhancement of predation through within-field diversification, pp. 121-160. In C. H. Pickett and R. L. Bugg [eds.], Enhancing Biological control. University of California Press, Berkeley.

Hukusima, S., and M. Kamei. 1970. Effects of various species of aphids as food on development, fecundity and longevity of Harmonia axyridis Pallas (Coleoptera: Coccinellidae). Res. Bull. Fac. Agric. Gifu Univ. 29: 53-66.

Johanowicz, D. L., and E. R. Mitchell. 2000. Effects of sweet alyssum flowers on the longevity of the parasitoid wasp Cotesia marginiventris (Hymenoptera: Braconidae) and Diadegma insulare (Hymenoptera: Ichneumonidae). Fl. Entomol. 83: 41-47. 
Jones, G. A., and J. L. Gillett. 2005. Intercropping with sunflowers to attract beneficial insects in organic agriculture. Fl. Entomol. 88: 91-96.

Koch, R. L. 2003. The multicolored Asian lady beetle, Harmonia axyridis: a review of its biology, uses in biological control, and non-target impacts. J. Insect Sci. 3: 1-16.

LaMana, M. L., and J. C. Miller 1996. Field Observations on Harmonia axyridis Pallas (Coleoptera: Coccinellidae) in Oregon. Biocontrol 6: 232-237.

McPherson, J.E. 1980. A list of the prey species of Podisus maculiventris (Hemiptera: Pentatomidae). Great Lakes Entomol. 13: 17-24.

Mensah, R. K. 1999. Habitat diversity: implications for the conservation and use of predatory insects of Helicoverpa spp. in cotton systems in Australia. Int. J. Pest Manage. 45: 91100.

Mondor, E. B., and J. L. Warren. 2000. Unconditioned and conditioned response to colour in the predatory coccinellid, Harmonia axyridis (Coleoptera: coccinellidae).Eur. J. Entomol. $97: 463-476$

Nalepa, C. A., K. A. Kidd, and D. I. Hopkins. 2000. The multicolored Asian ladybeetle (Coleoptera: Coccinellidae): Orientation to aggregation sites. J. Entomol. Sci. 35: 150157.

Nentwig, W. 1998. Weedy plant species and their beneficial arthropods: potential for manipulation in field crops, pp. 49-73 In C. H. Picket and R. L. Bugg (ed), Enhancing Biological Control. Univ. of California Press, Berkeley, CA.

Obata, S., Y. Johki, and T. Hidaka. 1986. Location of hibernation sites in the ladybird beetle, Harmonia axyridis, pp. 193-198. In I. Hodek (ed.), Ecology of Aphidophaga. Academia, Prague, Netherland. 
Pickett, C. H., and Bugg, R. L.1998. Introduction: Enhancing biological control-habitat management to promote natural enemies of agricultural pests, pp. 1-24. In C. H. Pickett and R. L. Bugg [eds.], Enhancing Biological control. University of California Press, Berkeley.

Rodenhouse, N. L., G. W. Berrett, D. M. Zimmerman, and J. C. Kemp. 1992. Effects of uncultivated corridors on arthropod abundances and crop yields in soybean agroecosystems. Agric. Econ. Environ. 38: 179-191.

SAS Institute. 2008. SAS OnlineDoc ${ }^{\circledR}$ version 9.1.3. SAS Institute. Cary, NC.

Schaller, M., and W. Nentwig. 2000. Olfactory orientation of the seven-spot ladybird beetle, Coccinella septempunctata (Coleoptera: Coccinellidae): attraction of adults to plants and conspecific females. Eur. J. Entomol. 97: 155-159.

Schoenig, S. E., R. L. Bugg, and J. Utts. 1998. The role of experimentation in the development of enhancement strategies, pp. 271-298 In C. H. Picket and R. L. Bugg [eds.], Enhancing Biological Control. Univ. of California Press, Berkeley, CA.

Seagraves, M. P., and K. V. Yeargan. 2006. Selection and evaluation of a companion plant to indirectly augment densities of Coleomegilla maculata (Coleoptera: Coccinellidae) in sweet corn. Environ. Entomol. 35: 1334-1341

Sokal, R. R. and F. J. Rohlf. 1998. Biometry. W. H. Freeman and Company, New York. 887 pp.

Souissi, R., N'enon, J. P., and LeR* u, B. (1998). Olfactory responses of the parasitoid Apoanagyrus lopezi to odor of plants, mealybugs and plant-mealybug complexes. J. Chem. Ecol. 24: 37-48. 
Takabayashi, J. and M. Dicke. 1992. Response of predatory mites with different rearing histories to volatiles of uninfested plants. Entomol. Exp. Appl. 64: 187-193.

Tedders, W. L., and P. W. Schaefer. 1994. Release and establishment of Harmonia axyridis (Coleoptera: Coccinellidae) in the southeastern United States. Entomol. News 105: 228243.

Wratten, S. D., H. F. Van emden, and M. B. Thomas. 1998. Within-field and border refugia for the enhancement of natural enemies, pp. 375-404 In C. H. Picket and R. L. Bugg [eds.]. Enhancing Biological Control. Univ. of California Press, Berkeley, CA. 
Table 1: Preference of $H$. axyridis to ten selected plants with no plant, Chi-square test was used to test the preference

\begin{tabular}{lllll}
\hline Plant & $\mathrm{X}^{2}$ & $\mathrm{df}$ & $P$ & Flowering Time \\
\hline Dandelion & 11.520 & 1 & 0.007 & June \\
Bugleweed & 13.520 & 1 & 0.000 & June \\
Marigold & 3.920 & 1 & 0.047 & June \\
Yarrow & 0.000 & 1 & 1.000 & September \\
Butterflyweed & 13.520 & 1 & 0.000 & August \\
Dill & 5.120 & 1 & 0.023 & October \\
Morning glory & 0.080 & 1 & 0.777 & October \\
Goldenrod & 0.720 & 1 & 0.396 & September \\
Sunflower & 11.520 & 1 & 0.001 & October \\
Tansy & 2.000 & 1 & 0.157 & September \\
\hline
\end{tabular}


Table 2: Average ( \pm SE) number of male, female and combined of Harmonia axyridis found on six different colors

\begin{tabular}{llll}
\hline Color & Male & Female & Combine \\
\hline Yellow & $2.4 \pm 1.26 \mathrm{a}^{*}$ & $2.8 \pm 1.23 \mathrm{a}$ & $5.2 \pm 1.23 \mathrm{a}$ \\
Green & $1.3 \pm 1.16 \mathrm{~b}$ & $1.5 \pm 1.27 \mathrm{~b}$ & $2.8 \pm 1.19 \mathrm{~b}$ \\
Orange & $0.4 \pm 0.52 \mathrm{c}$ & $0.0 \pm 0.00 \mathrm{c}$ & $0.4 \pm 0.41 \mathrm{dc}$ \\
Blue & $0.1 \pm 0.32 \mathrm{c}$ & $0.2 \pm 0.63 \mathrm{c}$ & $0.3 \pm 0.49 \mathrm{~d}$ \\
Red & $0.2 \pm 0.42 \mathrm{c}$ & $0.0 \pm 0.00 \mathrm{c}$ & $0.2 \pm 0.31 \mathrm{~d}$ \\
White & $0.7 \pm 1.25 \mathrm{bc}$ & $0.4 \pm 0.52 \mathrm{c}$ & $1.1 \pm 0.94 \mathrm{c}$ \\
\hline
\end{tabular}

*Mean within each variable in each column followed by the same letter are not significantly different $(P>0.05$; Tukey's standardized range test $)$. 


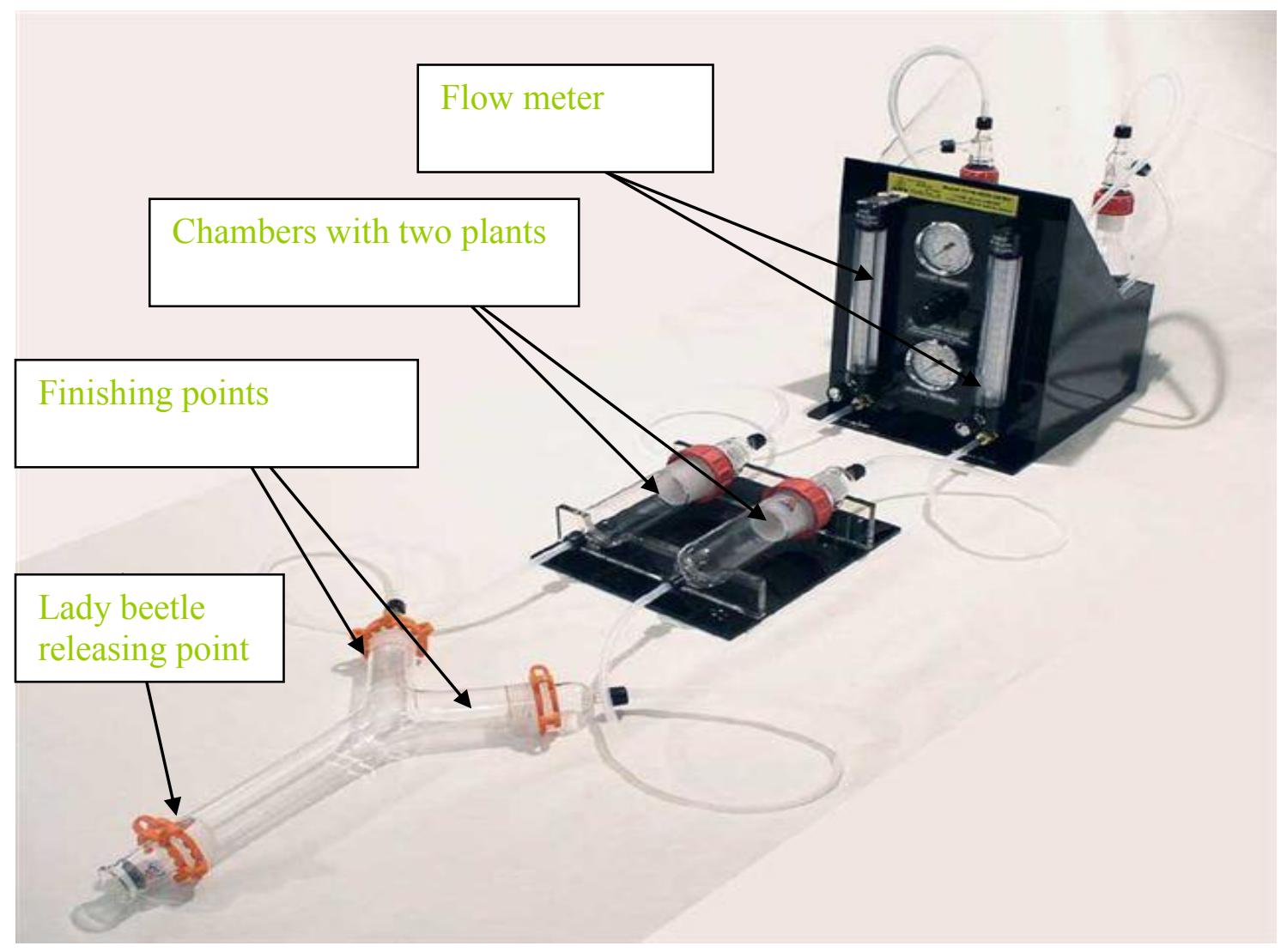

Figure 1. Y-tube olfactory meter used for choice test examining the preference of $\boldsymbol{H}$. axyridis in response to two compared plants. 


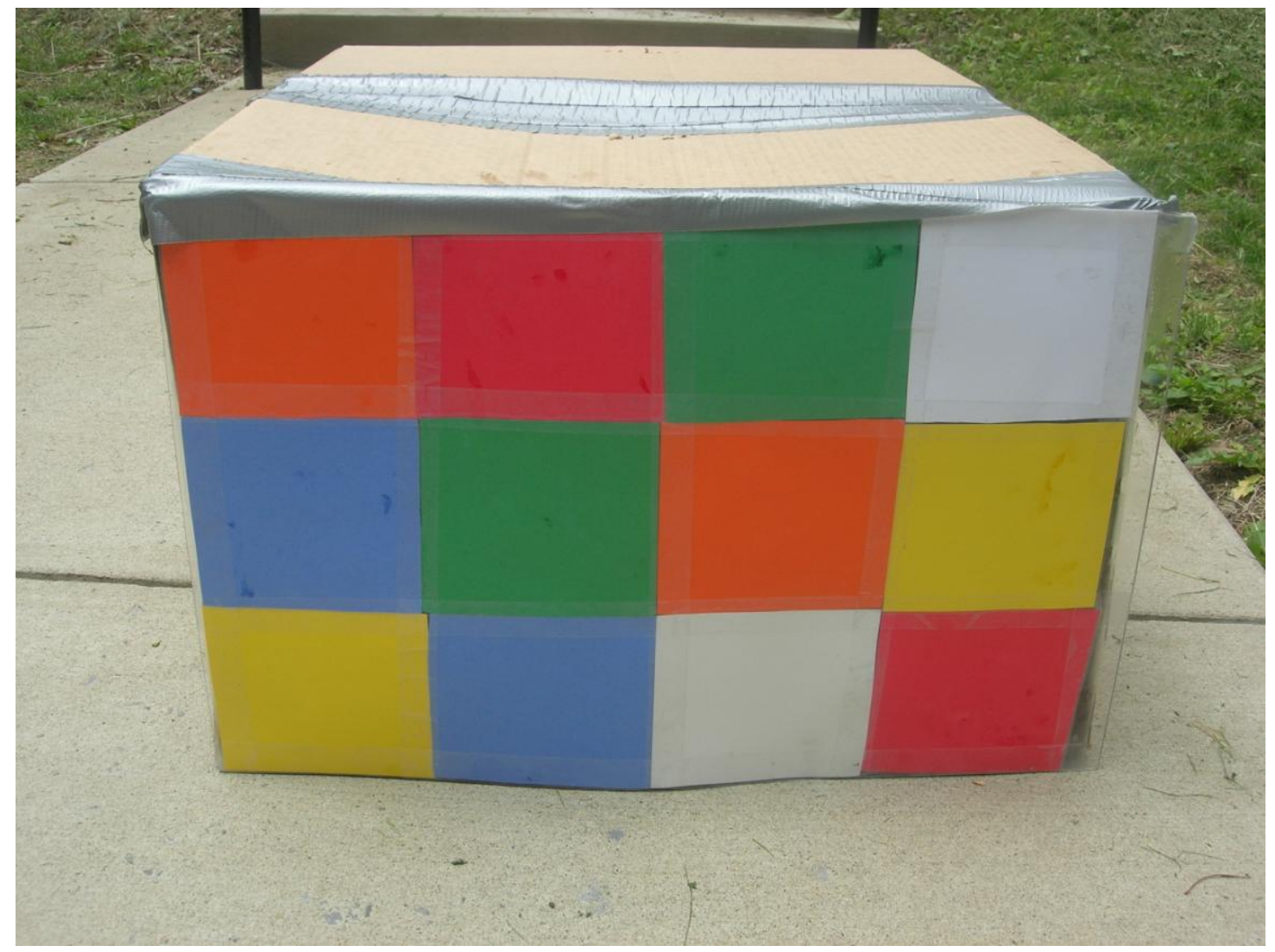

Figure 2. Rectangle box used for visual test examining the preference of $\boldsymbol{H}$. axyridis in response to six different colors (yellow, green, blue, orange, red and white). 


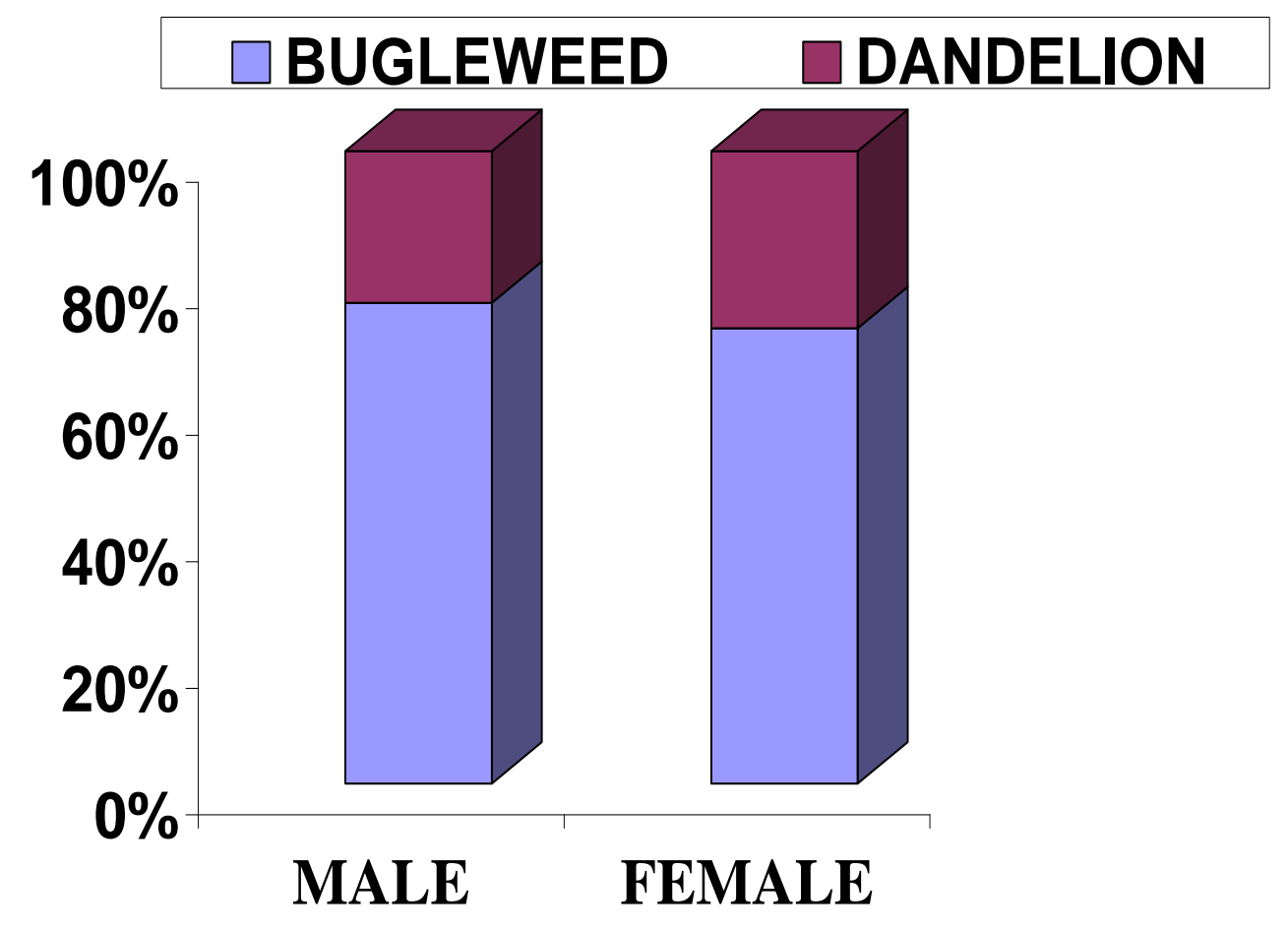

Figure 3. Preference of male and female $\boldsymbol{H}$. axyridis to bugleweed vs dandelion Chi-square test was used to test the preference. 


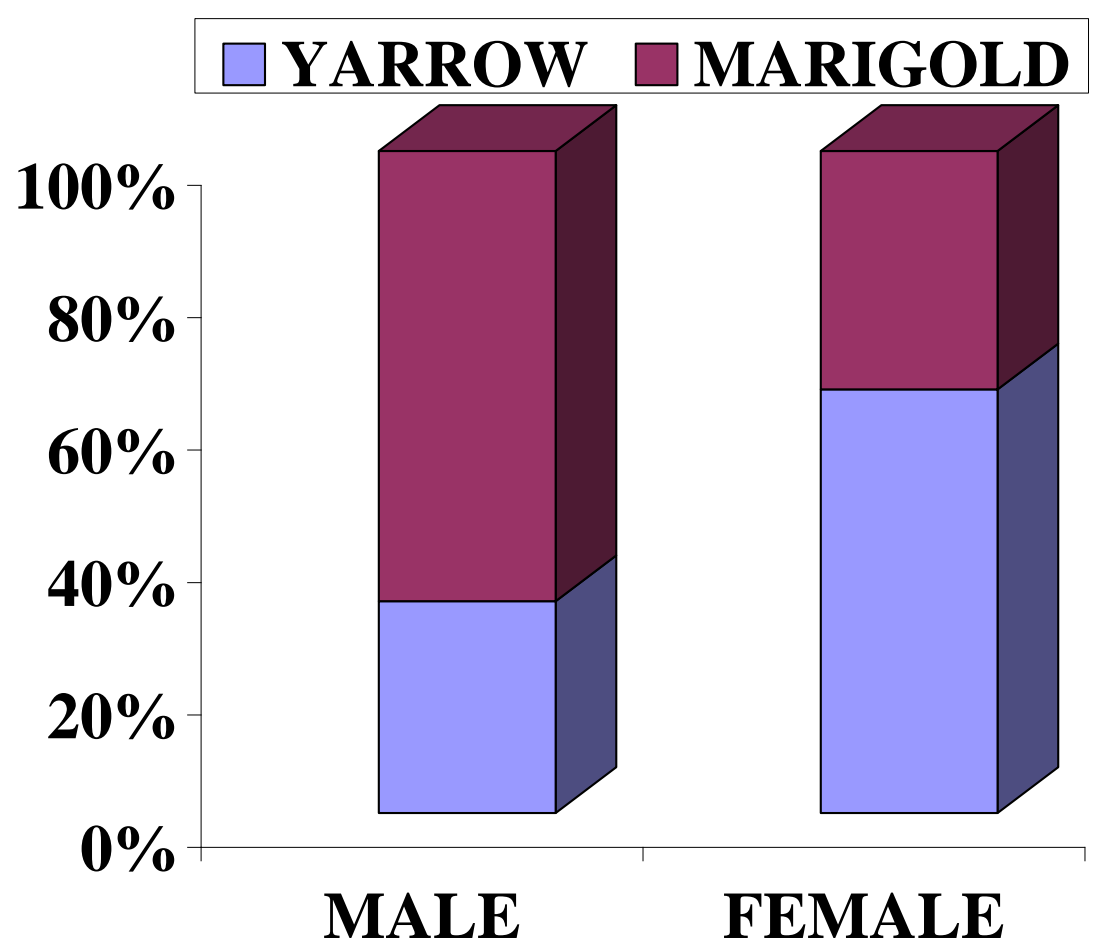

Figure 4. Preference of male and female $\boldsymbol{H}$. axyridis to yarrow vs marigold. Chi-square test was used to test the preference. 


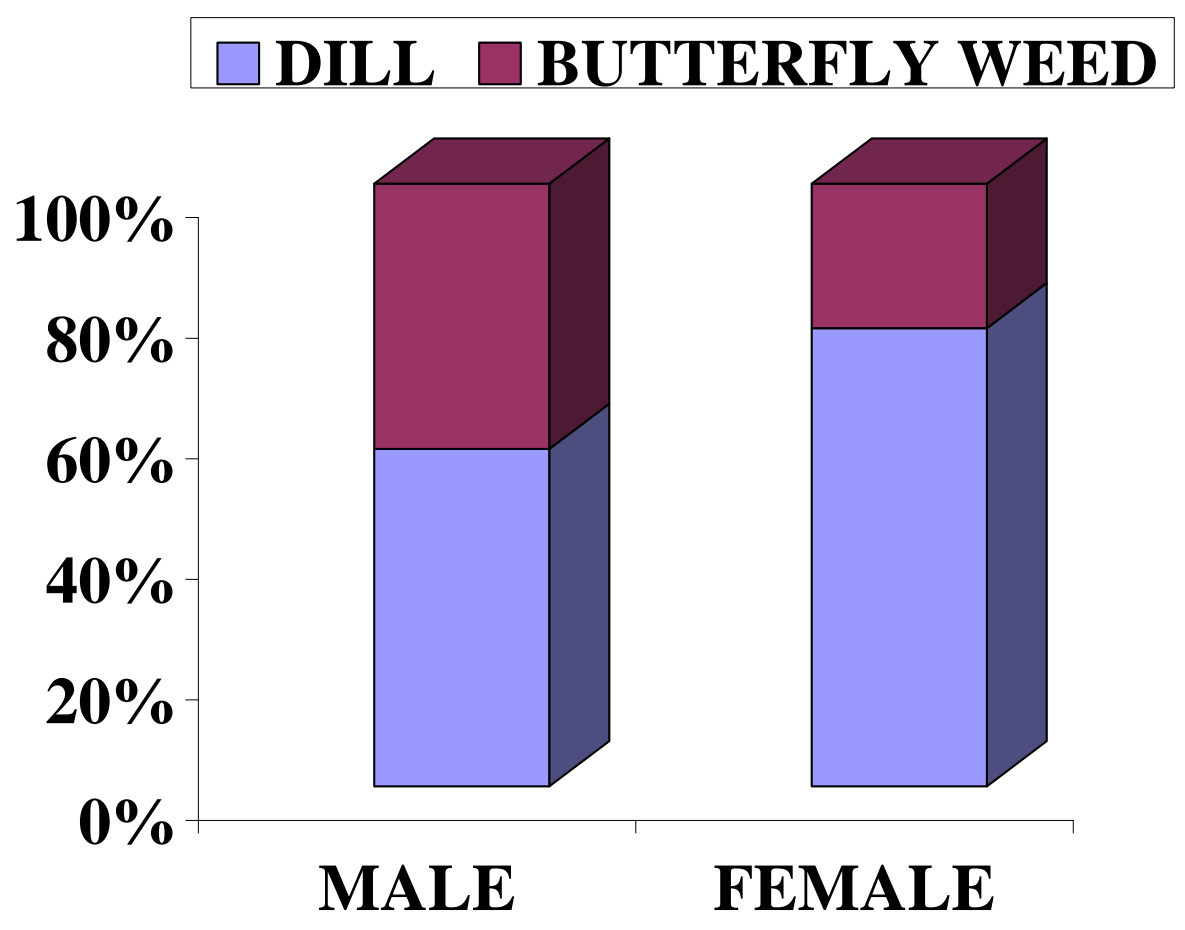

Figure 5. Preference of male and female $\boldsymbol{H}$. axyridis to dill vs butterfly weed. Chi-square test was used to test the preference. 


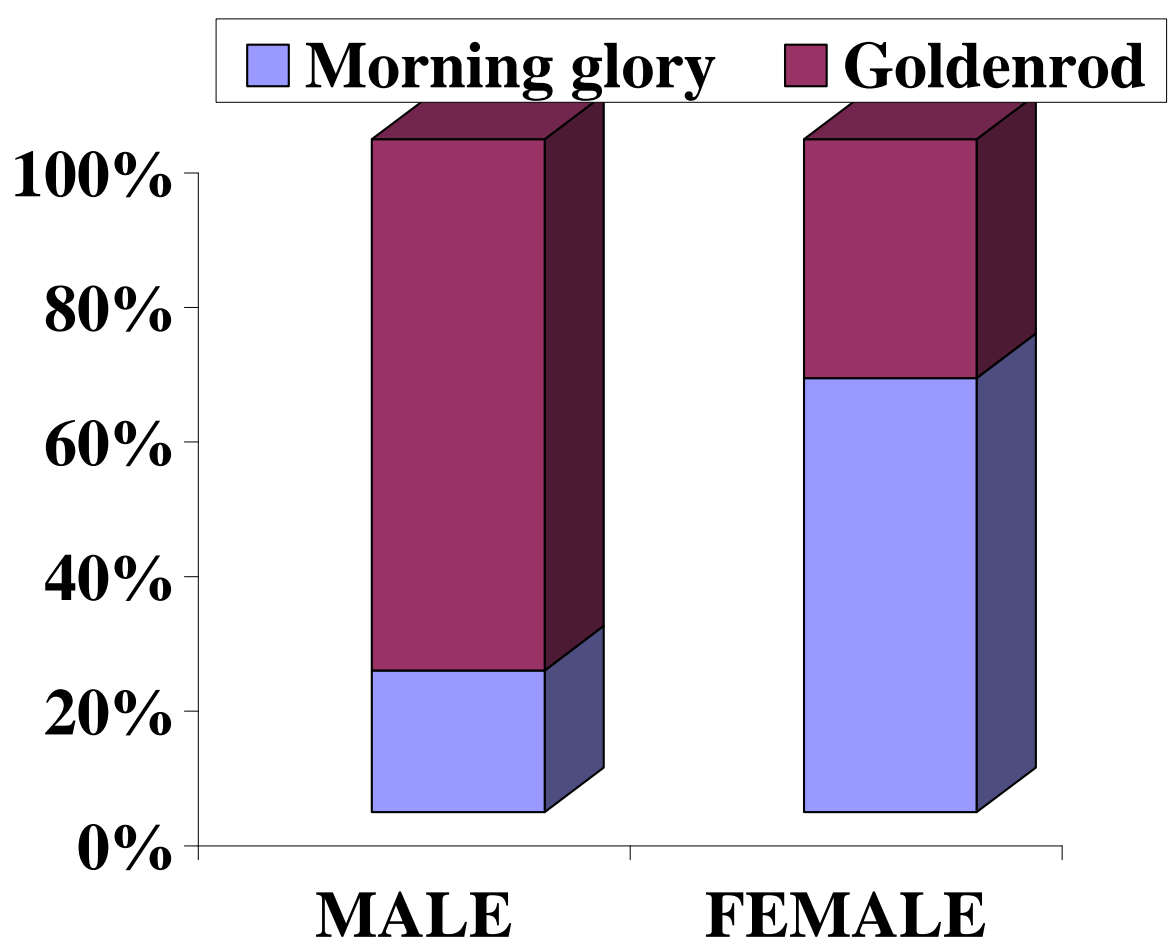

Figure 6. Preference of male and female $\boldsymbol{H}$. axyridis to morning glory vs goldenrod. Chisquare test was used to test the preference. 


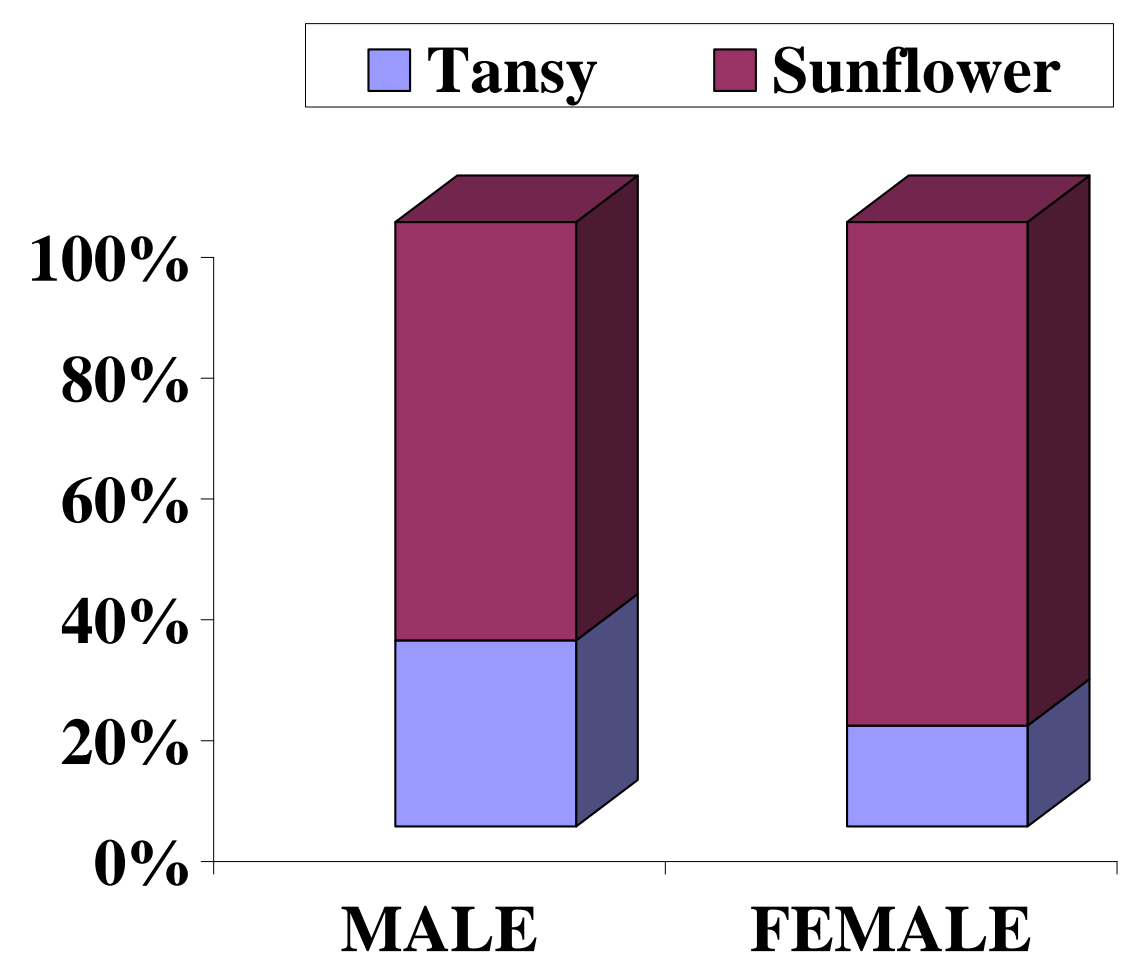

Figure 7. Preference of male and female $H$. axyridis to tansy vs sunflower. Chi-square test was used to test the preference. 


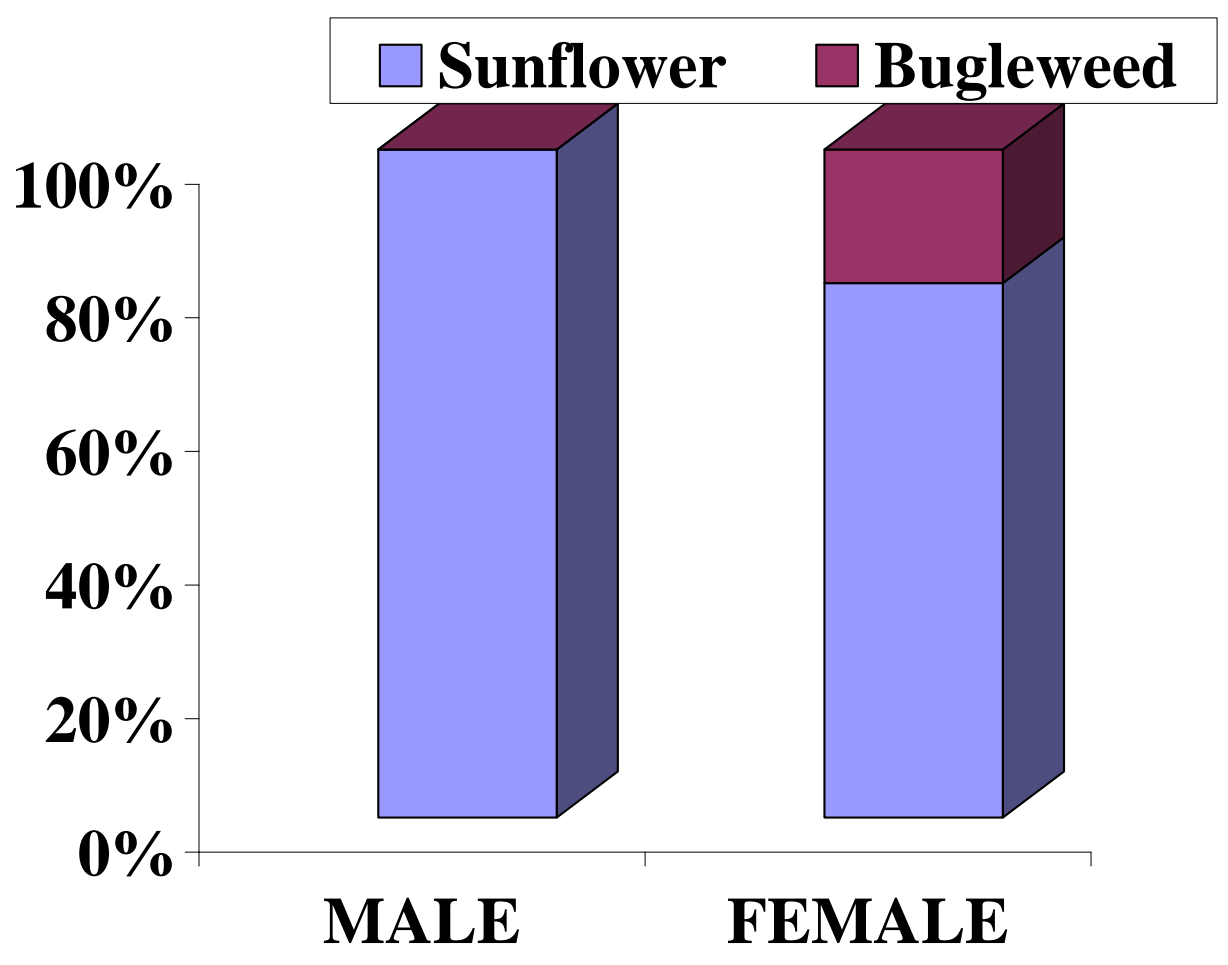

Figure 8. Preference of male and female $\boldsymbol{H}$. axyridis to sunflower vs bugleweed. Chi-square test was used to test the preference. 


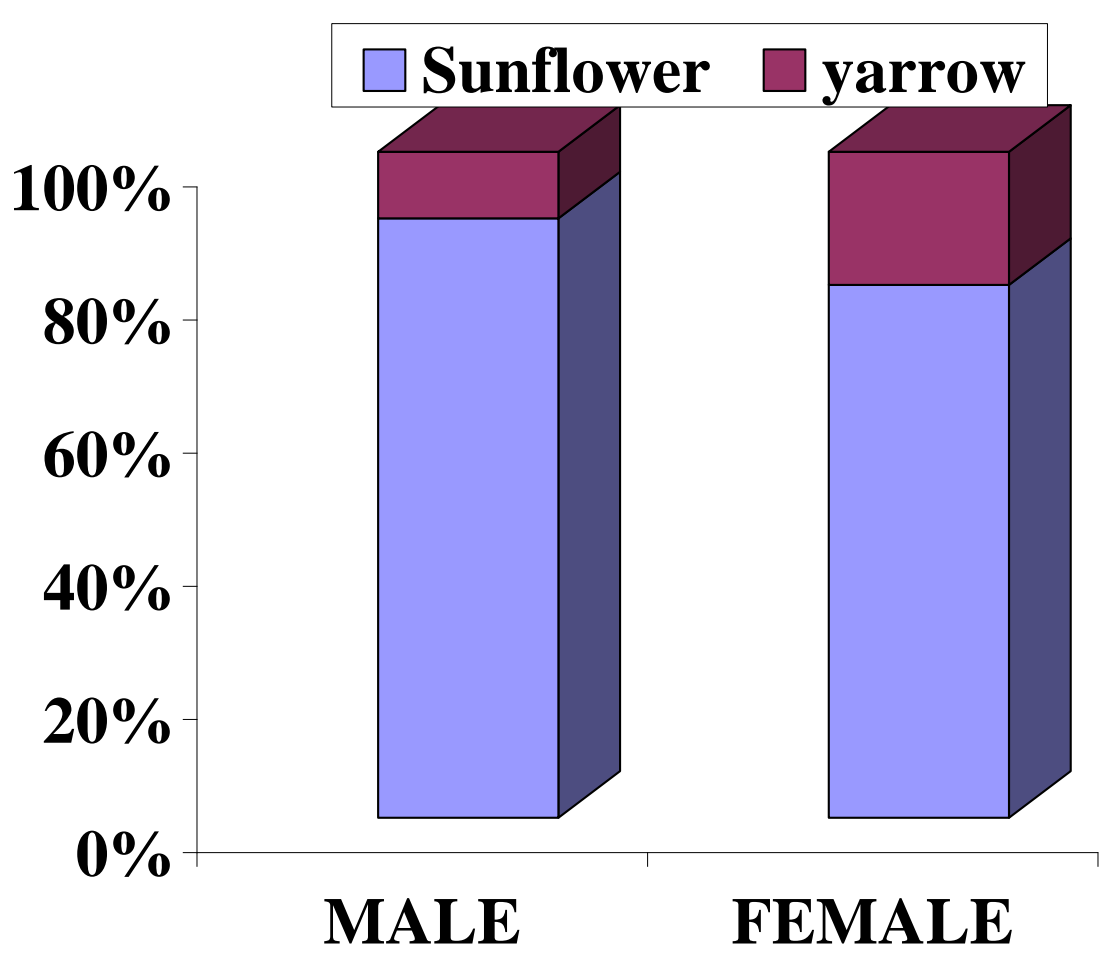

Figure 9. Preference of male and female $\boldsymbol{H}$. axyridis to sunflower vs yarrow. Chi-square test was used to test the preference. 


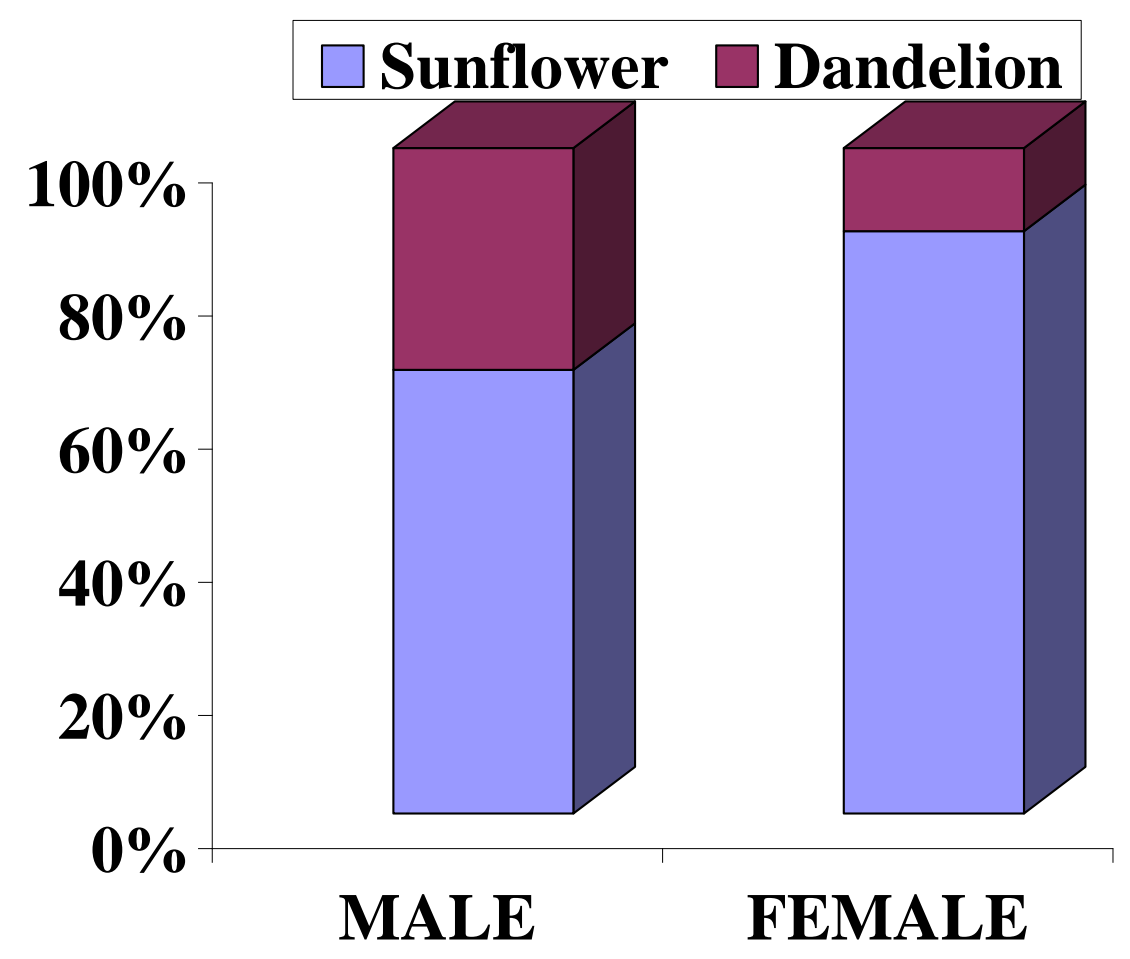

Figure 10. Preference of male and female $H$. axyridis to sunflower vs dandelion. Chi-square test was used to test the preference. 


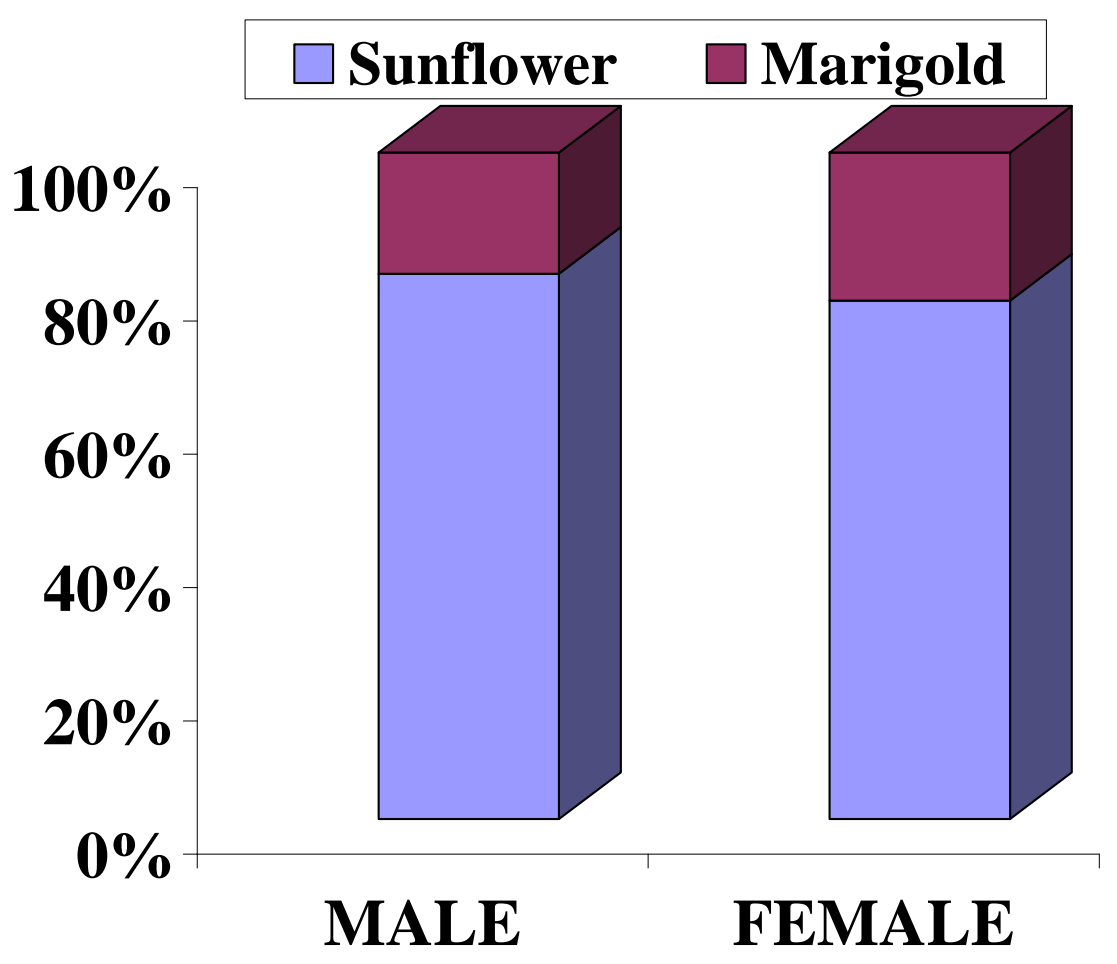

Figure 11. Preference of male and female $\boldsymbol{H}$. axyridis to sunflower vs marigold. Chi-square test was used to test the preference. 


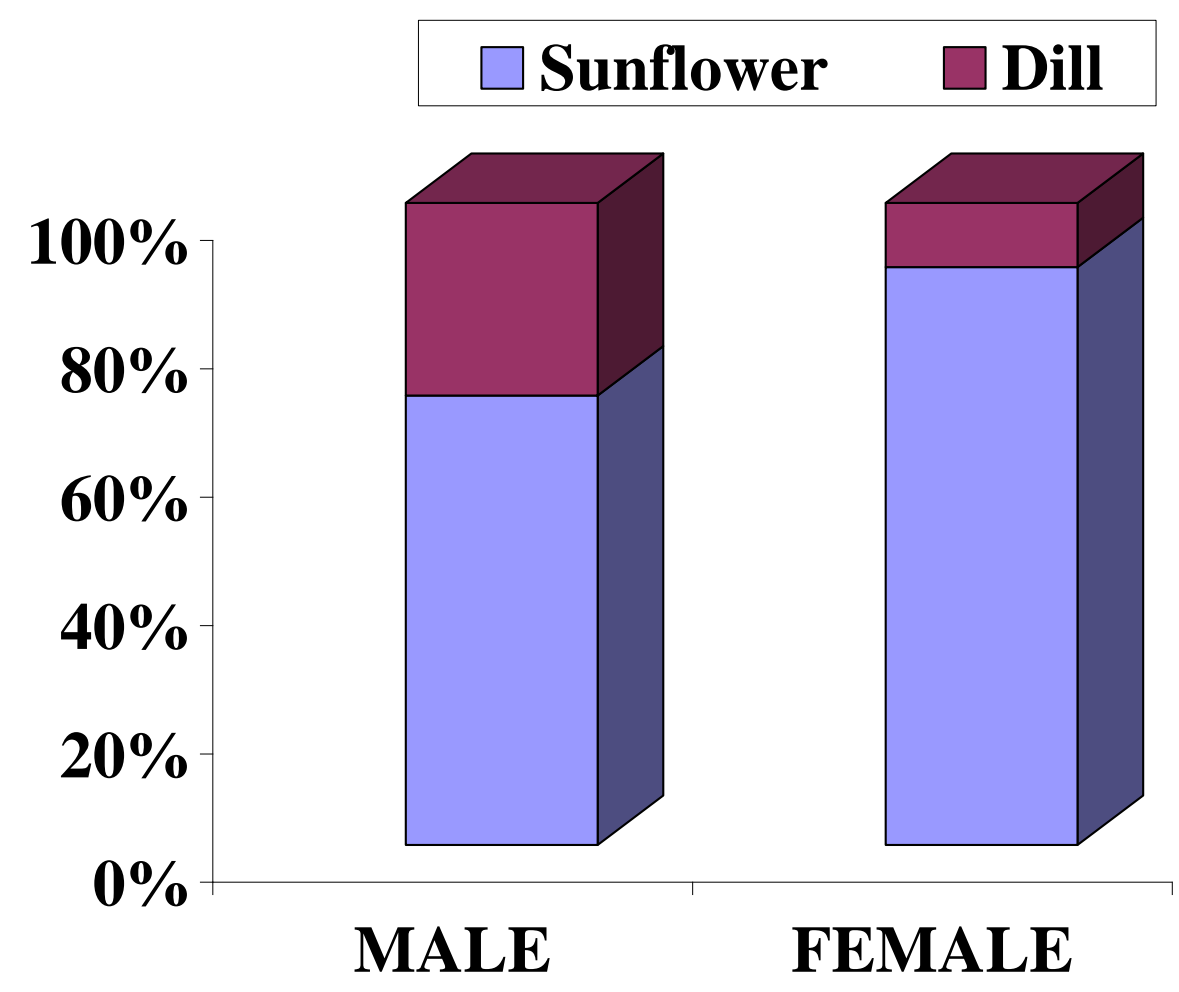

Figure 12. Preference of male and female $H$. axyridis to sunflower vs marigold. Chi-square test was used to test the preference. 


\title{
CHAPTER 3: EFFECT OF WITHIN PLANT DISTRIBUTION AND SIZE OF MEALYBUG (PREY) ON SEARCHING BEHAVIOR OF CRYPTOLAEMUS MONTROUZIERI (COLEOPTERA: COCCINELLIDAE)
}

\begin{abstract}
This study was conducted to investigate within-plant distribution of long-tailed mealybug, Pseudococcus longispinus (Targioni-Tozzetti) (Hemiptera: Pseudococcidae) to quantify the searching and handling time of Cryptolaemus montrouzieri (Coleoptera: Coccinellidae), and to determine preference of $C$. montrouzieri to the size of P. longispinus. Distribution of $P$. longispinus was investigated on three different heights of plants including Ficus elastica (Alismatales: Araceae) (tall plant category), Lilium longiflorum (Liliales: Liliaceae) (medium plant) and Dieffenbachia seguine (Alismatales: Araceae) (short plant). Preference of $C$. montrouzieri to the size of $P$. longispinus prey was also examined. On average, P. longispinus were found more on the upper parts of the plants regardless of the height. The time $C$. montrouzieri spent to find the first $P$. longispinus was significantly $(P<0.05)$ different among the three different plant heights at two different releasing points. This indicates that releasing C. montrouzieri adults from the top or on smaller plants could reduce searching time for $P$. longispinus. However, there were no significant differences in handling time and cleaning time. Cryptolaemus montrouzieri preferred smaller size of P. longispinus to medium and larger size. There were no significant differences in handling time, but there were significant differences in cleaning time that was observed among different sizes of $P$. longispinus. The implications for the use of C. montrouzieri in biological control are also discussed.
\end{abstract}

Keywords: Mealybug destroyer, long-tailed mealybug, choice test, preference, distribution 
The long-tailed mealybug, Pseudococcus longispinus (Targioni-Tozzetti) (Hemiptera: Pseudococcidae), is a key pest of fruit trees and ornamental plants (Ben-Dov and Germain 2003). P. longispinus feeds on various plant parts including roots, trunk, cordon, canes, leaves and fruit, causing aesthetic damage or yield loss. Molds that grow on the honeydew excreted by $P$. longispinus can cause further economic damage on crops. High P. longispinus densities often cause leaf drop and reductions of crop quality and yield; Uygun (2001) reported that yield loss of citrus by $P$. longispinus could be up to $80-90 \%$. P. longispinus also can transmit viral diseases in grapevines (Acheche et al. 1999). Chemical control of P. longispinus is difficult because it produces thick layers of protective wax and can hide in bark crevices, spurs, or canes. In general, chemical control is effective when $P$. longispinosus is in the crawler stage and when the host plants do not provide P. longispinosus with enough shelters for protection (Furness 1977). Therefore, biological control using natural enemies has been a major alternate method to control P. longispinus (Cooper 1985).

Natural enemies that can control P. longispinus include lady beetles, parasitic wasps, and lacewings. Among the natural enemies, the mealybug destroyer, Cryptolaemus montrouzieri Mulsant (Coleoptera: Coccinellidae), is one of the key natural enemies of $P$. longispinus in the United States. C. montrouzieri is native to Australia and has been used to control many mealybug species throughout the world (Bartlett 1974, 1978). C. montrouzieri was first imported into the United States in the late 1800s to control citrus mealybugs in California (Sadof 1995). Since then, C. montrouzieri has been commercially available to control mealybugs throughout the United States. In an established population, immature stages of $C$. montrouzieri dominate the stable age distribution and most prey is consumed by the larvae. However, $C$. 
montrouzieri adults are released to initiate biological control of $P$. longispinus because of their ability to disperse and search for mealybugs.

Effectiveness of natural enemies controlling pests is dependent upon how they can establish populations in a given environment and how effectively the natural enemy can find prey within a short period (Garcia and O'Neal 2000). Previous studies showed that natural enemies' ability to establish and search for prey was affected by plant structure and size (Price et al. 1980; Lawton 1983; Andow and Prokrym 1990; Kareiva and Sahakian 1990; Grevstad and Kleptka 1992). Garcia and O’Neal (2000) showed that plant size and variegation affected the searching efficiency of $C$. montrouzieri and Merlin et al. (1996) found that oviposition of $C$. montrouzieri was stimulated by wax filaments produced by its prey. These studies also indicated that successful biological control of $P$. longispinus would be affected by how efficiently $C$. montrouzieri adults search for $P$. longispinus after release. Key factors influencing prey search efficiency of $C$. montrouzieri finding $P$. longispinus may include release location of $C$. montrouzieri based on within-plant distribution of $P$. longispinus, the plant types, and stages of P. longispinus that $C$. montrouzieri prefers.

This study was conducted to investigate searching efficiency of $C$. montrouzieri to control P. longispinus on various ornamental plants. The objectives of this study were (1) to investigate within-plant distribution of $P$. longispinus, (2) to quantify the searching and handling time of $C$. montrouzieri related to releasing location, and (3) to determine preference of $C$. montrouzieri for the size of $P$. longispinus.

\section{MATERIALS AND METHODS}

Experiment 1: Within-plant distribution of $\boldsymbol{P}$. longispinus. Three different categories of plants based on height (tall, medium, and short) were grown in the greenhouse at West 
Virginia University (Monongalia County, WV). These plants included Ficus elastica (Alismatales: Araceae) (tall plant category), Lilium longiflorum (Liliales: Liliaceae) (medium plant) and Dieffenbachia seguine (Alismatales: Araceae) (short plant) and their heights were taken $(92 \mathrm{~cm} ; 94 \mathrm{~cm} ; 91 \mathrm{~cm} ; 93 \mathrm{~cm} ;$ and $86 \mathrm{~cm}),(61 \mathrm{~cm} ; 54 \mathrm{~cm} ; 44 \mathrm{~cm} ; 51 \mathrm{~cm} ; 42 \mathrm{~cm})$ and $(23 \mathrm{~cm}$;

$31 \mathrm{~cm} ; 25 \mathrm{~cm} ; 28 \mathrm{~cm} ; 37 \mathrm{~cm}$ ) respectively. Each plant was divided into two parts (top and bottom) and the number of $P$. longispinus were counted on each part of the plant. This experiment was replicated five times. Density of $P$. longispinus on top and bottom of the plants was analyzed with ANOVA and comparisons among plant heights were based upon Tukey's HSD test at $0.05 \%$ (SAS Institute 2008).

Experiment 2: Prey searching behavior of $C$. montrouzieri adults with respect to three different plant heights. Cryptolaemus montrouzieri adults were obtained from Peaceful Valley Farm Supply (Grass Valley, CA). Cryptolaemus montrouzieri were fed with $P$. longispinus collected from infested plants in the greenhouse at West Virginia University. Cryptolaemus montrouzieri were kept in ventilated cages with $P$. longispinus and a honey-water solution under laboratory conditions of $25^{\circ} \mathrm{C}$ and 16:8 (L:D) h photoperiod. All C. montrouzieri adults were denied access to prey but had access to water for the 12 -h period preceding all experiments. Searching, handling and cleaning time of $C$. montrouzieri were measured on three different plants. These plants included Ficus elastica (Alismatales: Araceae) (tall plant category), Lilium longiflorum (Liliales: Liliaceae) (medium plant) and Dieffenbachia seguine (Alismatales: Araceae) (short plant) and their heights were taken $(92 \mathrm{~cm} ; 94 \mathrm{~cm} ; 91 \mathrm{~cm} ; 93 \mathrm{~cm}$; and $86 \mathrm{~cm})$, $(61 \mathrm{~cm} ; 54 \mathrm{~cm} ; 44 \mathrm{~cm} ; 51 \mathrm{~cm} ; 42 \mathrm{~cm})$ and $(23 \mathrm{~cm} ; 31 \mathrm{~cm} ; 25 \mathrm{~cm} ; 28 \mathrm{~cm} ; 37 \mathrm{~cm})$ respectively. Searching, handling and cleaning time (initiation of feeding to cessation of feeding) was observed and recorded. Height was measured along the main stem, from the top of the soil to the 
top of the plant. On each plant, one $C$. montrouzieri adult was released from the top and another from the bottom of the plant to compare the searching, handling and cleaning time of finding $P$. longispinus. This experiment was replicated five times using different $C$. montrouzieri adults. The searching, handling and cleaning time of finding $P$. longispinus was recorded and analyzed with ANOVA (SAS Institute 2008).

Experiment 3: Three way preference for different mealybug prey size. A total of 20 C. montrouzieri adults were denied access to prey but had access to water for the 12 -h period preceding all experiments. Preference of $C$. montrouzieri for three stages of $P$. longispinus $1^{\text {st }}$ instar $(0.3 \mathrm{~mm}), 2^{\text {nd }}$ instar $(1.3 \mathrm{~mm})$ and adult $(3 \mathrm{~mm})$ was investigated using a Petri dish $(9 \mathrm{~cm}$ diameter) containing a single leaf of Ficus elastica (Alismatales: Araceae) (Fig. 1). Three of each size of $P$. longispinus was randomly placed on the leaf for each replication. One $C$. montrouzieri adult was placed in the center of the Petri dish and allowed to search for P. longispinus. Cryptolaemus montrouzieri adults choice among three different stages of $P$. longispinus and handling time were measured. This experiment was replicated 20 times. The result of the experiment was analyzed for significance by a Chi-square test (Sokal and Rohlf 1998).

\section{RESULTS}

Vertical distribution of $P$. longispinus varied considerably on plants. There were no significant differences in density of $P$. longispinus on the top $(F=0.46 ; \mathrm{df}=2,14 ; P>0.6491)$ and bottom $(F=0.94 ; \mathrm{df}=2,14 ; P=0.4427)$ among the plants used in this study. However, we found that significantly $(F=57.4 ; \mathrm{df}=1,29 ; P<0.0001)$ more $P$. longispinus were found on the upper parts of the plants regardless of the height (tall, medium and short) (Table 1.).

The time Cryptolaemus montrouzieri spent to find the first $P$. longispinus was significantly different among the three different plant heights (tall, medium and short) $(F=$ 
$10.19 ; \mathrm{df}=3,26 ; P=0.0001)$ and the two different releasing points (top and bottom) $(F=12.06$; $\mathrm{df}=5,24 ; P=0.001)$. Cryptolaemus montrouzieri spent significantly more time searching for $P$. longispinus on taller plants when they were released from the bottom (Table 2). However, there were no significant differences in handling time $(F=1.19 ; \mathrm{df}=3,26 ; P=0.3319)$ and cleaning time $(F=0.43 ; \mathrm{df}=3,26 ; P=0.7349)$. This indicates that releasing $C$. montrouzieri adults from the top or on smaller plants could reduce time searching for $P$. longispinus.

The results of the preference test of Cryptolaemus montrouzieri adults for three different sizes of $P$. longispinus $(0.3 \mathrm{~mm}, 1.3 \mathrm{~mm}$ and $3 \mathrm{~mm})$, showed that there was significant preference of $C$. montrouzieri adults for $P$. longispinus. (Chi-square $=9.109, \mathrm{df}=2$ and $P=$ 0.0105). C. montrouzieri preferred smaller P. longispinus to medium and larger sizes. There were no significant differences in handling time of $C$. montrouzieri feeding on different sizes of P. longispinus $(F=3.25 ; \mathrm{df}=2,17 ; P=0.0639)$, but there were significant differences in cleaning time among different sizes of $P$. longispinus $(F=8.14$; $\mathrm{df}=2,17 ; P=0.0033)$. This result indicates that cleaning time of $C$. montrouzieri after feeding on larger sizes of $P$. longispinus was significantly longer than the cleaning time after feeding on medium and smaller sizes (Table 3).

\section{DISCUSSION}

Within-plant distribution of pests is key information for determining where to release natural enemies to maximize efficiency of biological control because prey searching time could depend on the location for releasing natural enemies (Andow and Prokrym 1990, Yang and Sadof 1995). In this study, we showed that significantly more $P$. longispinus inhabited the upper part of plants regardless of plant types. This observation is in agreement with the finding by Flaherty et al. (1992) who showed higher population and movement of mealybugs toward the top 
of the plant. Because C. montrouzieri is known to be more effective when P. longispinus populations are high (Bartlett 1978; Moore 1988), releasing C. montrouzieri adults from the top of the plants could reduce prey searching time because $P$. longispinus is abundant on the upper part of plants. In addition, plant height could affect effectiveness of biological control by affecting prey searching efficiency of natural enemies (Garcia and O'Neil 2000). The results of our study indicated that effectiveness of $C$. montrouzieri increased when they are released on smaller plants. Therefore, the effectiveness of $C$. montrouzieri controlling $P$. longispinus could be maximized when $C$. montrouzieri are released from the top and on smaller plants.

This study also demonstrated that $C$. montrouzieri preferred to feed on smaller $P$. longispinus. When C. montrouzieri fed on larger larvae, they spent longer time in handling and cleaning after feeding and before searching for another prey. This result is congruent with Merlin et al. (1996) who found that C. montrouzieri consumed smaller P. longispinus nymphs first and then fed on larger nymphs or adults. Adult $C$. montrouzieri is known to be able to detect their prey by visual and chemical stimuli (Heidari and Copland 1992).

In conclusion, the results of this study suggest a major consideration on the use of $C$. montrouzieri to control $P$. longispinus. The efficiency of $P$. longispinus control by $C$. montrouzieri depends on the location of $C$. montrouzieri release and the plant height. Our study showed that effectiveness of $C$. montrouzieri controlling $P$. longispinus could be maximized when $C$. montrouzieri were released from the top of the plants and on the smaller plants; $C$. montrouzieri adults can reduce prey search time when they were released where P. longispinus is abundant. 


\section{ACKNOWLEDGEMENT}

I wish to thank Vicki Kondo and JB White at West Virginia University for their valuable support and suggestions related to this experiment. I also wish to thank Sue Myers at West Virginia University Green house for her help in identifying plants that were used in this research. This project was partially supported by the Division of Plant and Soil Science at West Virginia University and the Senate Grant Program at West Virginia University.

\section{REFERENCES CITED}

Acheche, H. S., Fattouch, S. Mhirsi, N. Marzouki, and M. Marrakchi. 1999. Use of optimized PCR methods for the detection of GLRaV3: a closterovirns associated with grapevine leafroll in Tunisian grapevine plants. Plant Mol. Biol. Rep. 17: 31-42.

Andow, D. A., and D. R. Prokrym. 1990. Plant structural complexity and host-finding by a parasitoid. Oecologia 82: 162-165.

Bartlett, B. R. 1974. Introduction into California of cold-tolerant biotypes of the mealybug predator, Cryptolaemus montrouzieri, and laboratory procedures for testing natural enemies for cold-hardness. Environ. Entomol. 3: 553-556.

Bartlett, B. R. 1978. Diaspididae, Eriococcidae, Margarodidae, Ortheziidae, Pseudococcidae, pp. 57-170. In C. P. Clausen (ed.), Introduced parasite and predators of Athropod pests and Weeds: a world review. U.S.D.A. Agriculture Handbook No. 480, Washington, D. C.

Ben-Dov, Y., and V. Germain. 2003. Scalenet: A Database of Scale Insects of the World. http://www.Sel.Barc.Usda.Gov. ScalenetScalenet.

Cooper, S. 1985. Cryptolaemus montrouzieri: A predator for mealybug. J. Br. Cact. Succ. 3: $38-39$. 
Flaherty, D. L., L. Christiensen, and W. T. Lanini. 1992. Mealybugs, pp. 159-165. In D. L. Flaherty, L. P. Christensen. W. T. Lanini, J. J. Marois, P. A. Phillips, and L. T. Wilson [eds.], Grape pest management. Univ. Calif. Div. Agric. Nat. Res. Publ. 3343. CA.

Furness, G. O. 1976. The dispersal, age-structure and natural enemies of the long-tailed mealybug, Pseudococcus longispinus (Targioni-Tozzetti), in relation to sampling and control. J. Aust. Zool. 24: 237-47.

Garcia, J. F., and R. J. O'Neil. 2000. Effect of Coleus size and variegation on attack rates, searching strategy, and selected life history characteristics of Cryptolaemus montrouzieri (Coleopteran: Coccinellidae) Biocontrol 18: 225-234.

Grevstad, F. S., and B. W. Klepetka. 1992. The influence of plant architecture on the foraging efficiencies of a suite of ladybird beetles feeding on aphids. Oecologia 92: 399-404.

Heidari, M., and M. J. W. Copland. 1992. Host finding by Cryptolaemus montrouzieri (Col., Coccinellidae) a predator of mealybugs (Homoptera: Pseudococcidae). Entomophaga 37: $621-625$.

Kareiva, P., and R. Sahakian. 1990. Tritrophic effects of a simple architectural mutation in pea plants. Nature 345: 433-434.

Lawton, J. H. 1983. Plant architecture and diversity of phytophagous insects. Annu. Rev. Entomol. 28: 23-39.

Merlin, J., O. Lemaitre, and J. C. Grégoire 1996. Oviposition in Cryptolaemus montrouzieri stimulated by wax filaments of its prey. Entomol. Exp. Appl. 79: 141-146.

Moore, D. 1988. Agents used for biological control of mealybugs (pseudococcidae). Biocontrol News Inform. 9: 209-225. 
Murray, D. A. H. 1978. Population studies of the citrus mealybug Planococcus citri (Risso), and it natural enemies on passion-fruit in south-eastern Queensland. J. Agric. Animal Sci. 35: $139-142$.

Price, P. W., C. E. Bouton, P. Gross, B. A. McPheron, J. N. Thompson, and A. E. Weis. 1980. Interactions among three trophic levels: Influence of plants on interactions between insect herbivores and natural enemies. Annu. Rev. Ecol. Syst. 11: 41-65.

Sadof, C. 1995. Know Your Friends: Mealybug Destroyer. www.oisat.org/control_methods/natural_enemies/predators/mealybug_destroyer.html.

SAS Institute. 2008. SAS OnlineDoc ${ }^{\circledR}$ version 9.1.3. SAS Institute. Cary, NC.

Uygun, N. 2001. Integrated pest management in Turkish citrus orchard. Agricultural Research Project Publications, Adana, Turkey (Turkish, with English abstract).

Yang, J., and C. S. Sadof. 1995. Variegation in Coleus blumei and the life history of citrus mealybug (Homoptera: Pseudococcidae). Environ. Entomol. 24: 1650-1655. 
Table 1: Average ( \pm SE) number of $P$. longispinus on the top and bottom part of plants of three different heights

\begin{tabular}{lll}
\hline Plant height* & Top & Bottom \\
\hline Short & $354 \pm 207 \mathrm{a}^{* *}$ & $90 \pm 71 \mathrm{~b}$ \\
Medium & $470 \pm 178 \mathrm{a}$ & $57 \pm 32 \mathrm{~b}$ \\
Tall & $418 \pm 115 \mathrm{a}$ & $49 \pm 36 \mathrm{~b}$ \\
\hline
\end{tabular}

$* 23 \mathrm{~cm}$ (Short), $51 \mathrm{~cm}$ (Medium) and $92 \mathrm{~cm}$ (Tall).

** Means within each variable in each row followed by the same letter are not significantly different $(P>0.05$; Tukey's standardized range test). 
Table 2: Searching, handling and cleaning time of $\mathrm{C}$. montrouzieri adults on different plant heights at two different releasing locations

\begin{tabular}{llllll}
\hline Plant height* & $\begin{array}{l}\text { Releasing } \\
\text { location on } \\
\text { plant }\end{array}$ & $\begin{array}{l}\text { Searching Time } \\
(\mathrm{min})\end{array}$ & $\begin{array}{l}\text { Handling } \\
\text { Time } \\
(\mathrm{min})\end{array}$ & $\begin{array}{l}\text { Cleaning } \\
\text { Time } \\
(\mathrm{min})\end{array}$ & $\begin{array}{l}\text { Total Time } \\
(\mathrm{min})\end{array}$ \\
\hline Short & Bottom & $4.60 \pm 1.14 \mathrm{bc} * *$ & $4.00 \pm 2.00 \mathrm{a}$ & $2.60 \pm 1.52 \mathrm{a}$ & $11.2 \pm 4.66 \mathrm{cb}$ \\
& Top & $2.40 \pm 0.55 \mathrm{c}$ & $3.40 \pm 1.14 \mathrm{a}$ & $2.20 \pm 1.64 \mathrm{a}$ & $8.0 \pm 3.33 \mathrm{c}$ \\
Medium & Bottom & $7.80 \pm 0.84 \mathrm{~b}$ & $4.40 \pm 1.14 \mathrm{a}$ & $2.20 \pm 1.10 \mathrm{a}$ & $14.4 \pm 3.08 \mathrm{~b}$ \\
& Top & $2.40 \pm 1.34 \mathrm{c}$ & $4.80 \pm 1.48 \mathrm{a}$ & $2.40 \pm 1.34 \mathrm{a}$ & $9.6 \pm 4.16 \mathrm{cb}$ \\
Tall & Bottom & $17.00 \pm 8.72 \mathrm{a}$ & $5.20 \pm 0.84 \mathrm{a}$ & $2.20 \pm 0.84 \mathrm{a}$ & $24.4 \pm 10.40 \mathrm{a}$ \\
& Top & $2.60 \pm 1.14 \mathrm{c}$ & $3.80 \pm 1.48 \mathrm{a}$ & $3.40 \pm 1.34 \mathrm{a}$ & $9.8 \pm 3.96 \mathrm{cb}$ \\
\hline
\end{tabular}

* $23 \mathrm{~cm}$ (Short), $51 \mathrm{~cm}$ (Medium) and 92cm (Tall).

** Means within each variable in each column followed by the same letter are not significantly different $(P>0.05$; Tukey's standardized range test). 
Table 3: Handling and cleaning time of $\mathrm{C}$. montrouzieri adults feeding on different sizes of mealybug

\begin{tabular}{llcl}
\hline Mealybug size* & $\begin{array}{c}\text { Handling time } \\
(\mathrm{min})\end{array}$ & $\begin{array}{c}\text { Cleaning Time } \\
(\mathrm{min})\end{array}$ & $\begin{array}{c}\text { Total } \\
(\mathrm{min})\end{array}$ \\
\hline Small & $6.9 \pm 2.18 \mathrm{a}^{* *}$ & $3.5 \pm 2.03 \mathrm{~b}$ & $10.4 \pm 4.21 \mathrm{~b}$ \\
Medium & $10.3 \pm 4.35 \mathrm{a}$ & $4.5 \pm 2.08 \mathrm{~b}$ & $14.8 \pm 6.43 \mathrm{ab}$ \\
Large & $12.0 \pm 7.00 \mathrm{a}$ & $8.7 \pm 1.53 \mathrm{a}$ & $20.7 \pm 8.53 \mathrm{a}$ \\
\hline
\end{tabular}

* Small (0.3 mm), Medium (1.3 mm) and Large (3 mm)

** Means within each variable in each column followed by the same letter are not significantly different $(P>0.05$; Tukey's standardized range test $)$ 


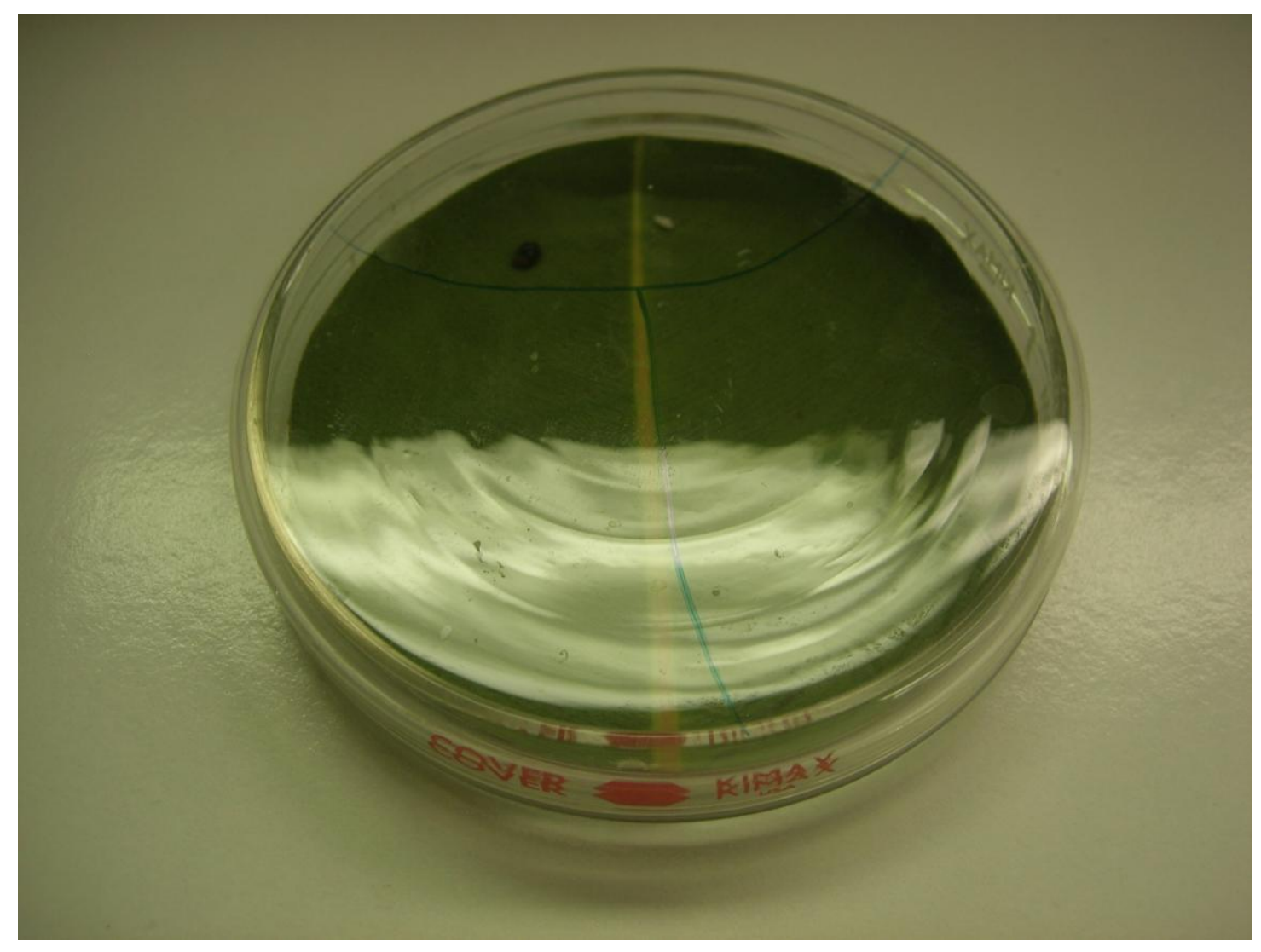

Fig. 1. The behaviour of $C$. montrouzieri in a 3-way food preference choice test between three stages of $P$. longispinus: $1^{\text {st }}$ instar $(0.3 \mathrm{~mm}), 2^{\text {nd }}$ instar $(1.3 \mathrm{~mm})$ and adult $(3 \mathrm{~mm})$. 


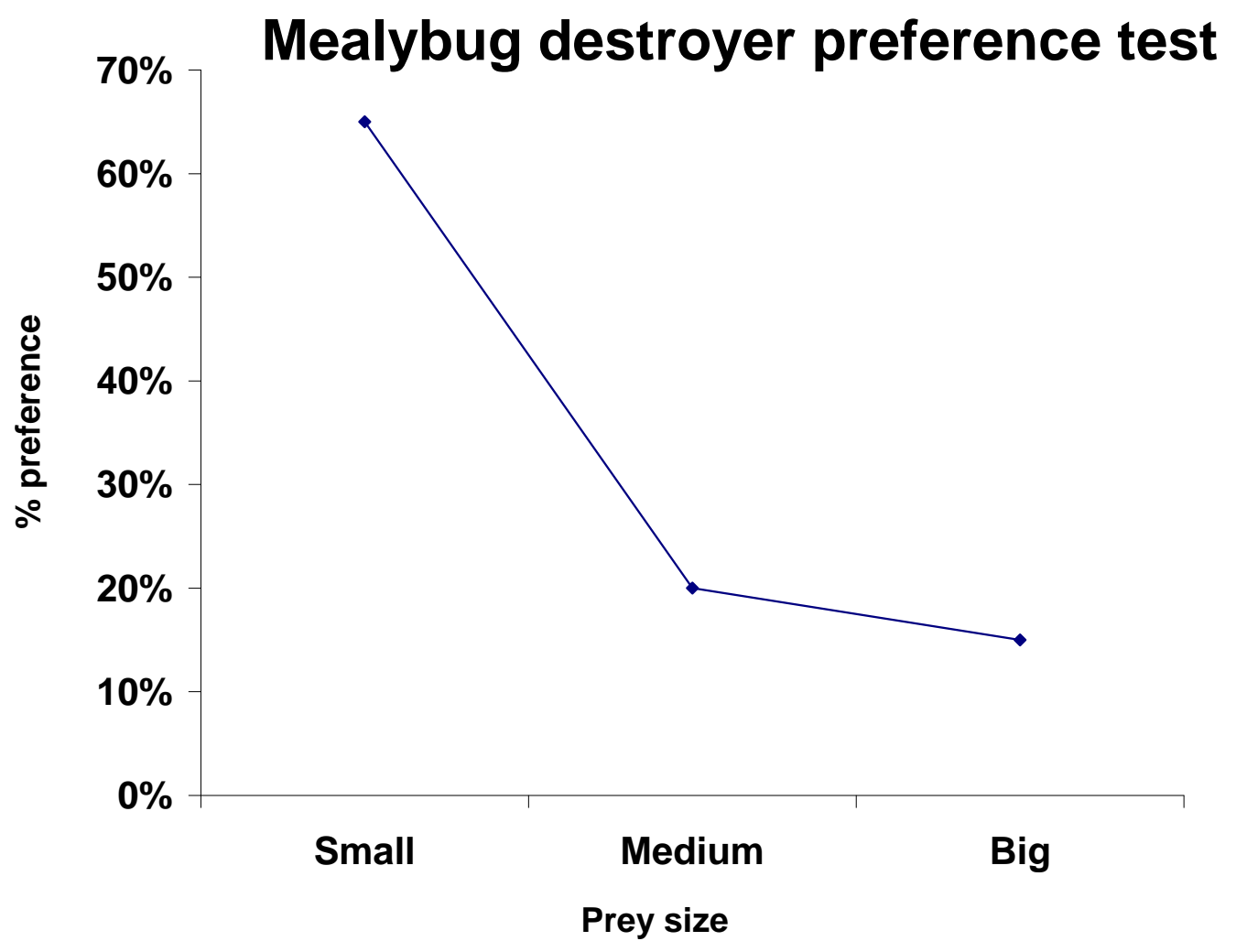

Figure 2. Preference of C. montrouzier to stages of P. longispinus: 1st instar $(0.3 \mathrm{~mm})$, 2nd instar $(1.3 \mathrm{~mm})$ and adult $(3 \mathrm{~mm})$. 


\section{CHAPTER 4: CONCLUSION}

Knowledge about how natural enemies use plant-based resources may lead to the ability to directly attract natural enemy populations to increase biological control. Harmonia axyridis adults reside on the farm during the growing season. Therefore, it is important to attract and keep them within the farm to control pest insects. H. axyridis can feed on aphids, mealybugs scale insects, and eggs of moths (Park and Obrycki 2004). Currently, H. axyridis has proved beneficial in suppressing pests such as corn leaf aphid (Seagraves and Yeargan 2006).

The result of this study (Chapter 2) indicates two major applications on how to attract $H$. axyridis adults. $H$. axyridis occurs in several agroecosystems and is considered an important predator on many significant economic pests. Our results suggest that it may be possible to attract this natural enemy to crops in which it already occurs by adding sunflower as a companion planting. Second, knowing the color of plants that $H$. axyridis prefers can also serve as a means of attracting them into cropping areas because when prey insects become scarce they tend to feed on pollen and nectar. Thus, such natural enemies can potentially be used as economical and sustainable biological control agents as long as they can be attracted and kept in the cropping areas within farms.

This study (Chapter 3) also reveals the implications of using Cryptolaemus montrouzieri as a biological control agent. Plant heights and position from which C. montrouzieri has been released for biological control has an impact on their effectiveness. For example, fewer predators would be needed to control pests on smaller plants when released from the top than on taller complex plants when released from the bottom. This indicates that releasing C. montrouzieri adults from the top or on smaller plants could reduce time spent searching for P. longispinus. This study also demonstrates that $C$. montrouzieri prefers to feed on $1^{\text {st }}$ instars of $P$. longispinus 
and will spend longer time in handling and cleaning after feeding on larger instars before moving on to another prey. The result of this study shows that care must be taken when using this predator as a biological control agent.

\section{REFERENCES CITED}

Park, Y. L., and J. J. Obrycki. 2004. Spatio-temporal distribution of corn leaf aphids (Homoptera: Aphididae) and lady beetles (Coleoptera: Coccinellidae) in Iowa cornfields. Biol. Contr. 31: 210-217.

Seagraves, M. P., and K. V. Yeargan. 2006. Selection and evaluation of a companion plant to indirectly augment densities of Coleomegilla maculata (Coleoptera: Coccinellidae) in sweet corn. Environ. Entomol. 35: 1334-1341.

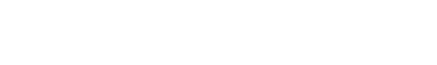

